\title{
Limites, desafios e perspectivas: a primeira década da revista História da Historiografia (2008-2018)
}

\section{Limits, challenges and perspectives: História da Historiografia journal during the first decade (2008-2018)}

\section{Flávia Florentino Varella}

\section{RESUMO}

Este artigo tem como principal objetivo avaliar o perfil dos editores executivos e dos autores, e as características técnicas das publicações do periódico científico História da Historiografia, no período de 2008 a 2018, por meio de indicadores bibliométricos. Utilizando dados disponíveis nas edições completas da revista, observouse que, o perfil principal dos autores de artigos é de homens $(68 \%)$, professores do ensino superior (55\%), professores adjuntos $(41 \%)$, vinculados a instituições brasileiras $(70 \%)$, situadas na região sudeste $(67 \%)$, que publicaram uma única vez no periódico (87\%). Os artigos são, em sua maioria, de autoria única (92\%), realizados sem financiamento $(67 \%)$, escritos em português $(80 \%)$, pertencentes à história da historiografia e à teoria da história (67\%), voltados ao estudo de autores ou aspectos do Brasil (25\%), focados na idade contemporânea (77\%). A maioria dos autores estudados nos artigos publicados na História da Historiografia são do sexo masculino (95\%). No que tange à composição de seu Conselho Executivo, a maioria dos pesquisadores são homens (86\%), brancos $(72 \%)$, brasileiros $(86 \%)$, lotados em instituições de ensino superior da região sudeste $(75 \%)$.

\section{PALAVRAS-CHAVE}

História da Historiografia; Revistas de História; Historiografia brasileira.

\section{ABSTRACT}

This study aims to evaluate the profile of the executive editors and the authors, and the technical characteristics of the publications of the História da Historiografia journal, from 2008 to 2018, through bibliometric analysis. Using data available in the complete editions of the journal, it was observed that the main profile of the authors of articles was men (68\%), higher education teachers (55\%), adjunct professors $(41 \%)$, from Brazilian institutions $70 \%$ ), located in the southeast region $(67 \%)$, who published only once in the jornal $(87 \%)$. The papers were mostly contributed in single author style (92\%), carried out without funding $(67 \%)$, written in Portuguese $(80 \%)$, belonging to the history of historiography and to the theory of history (67\%), of authors or aspects of Brazil (25\%), focused on the contemporary age (77\%). Most of the authors studied in the articles published in the História da Historiografia are male (95\%). Regarding the composition of its Executive Board, the majority of the researchers are men $(86 \%)$, whites $(72 \%)$, Brazilians $(86 \%)$, from institutions of higher education in the Southeast region (75\%).

\section{KEYWORDS}

History of Historiography; History journals; Brazilian historiography. 
A análise de revistas ligadas ao campo da história da historiografia e da teoria da história, como a Revue Historique, Annales e Historische Zeitschrift, mostra a importância desses loci editoriais na formação e consolidação de agendas e grupos de pesquisa em múltiplos contextos nacionais. Há algum tempo vem sendo salientado o grande potencial das revistas históricas na delimitação das tendências historiográficas (MELLO 2012a), na desmistificação de narrativas tradicionais (BENTIVOGLIO 2011) e na percepção dos interesses editorias envolvidos (OSÉS 2017), dentre tantas outras possibilidades investigativas. A crescente atividade periódica em finais do século XIX (TESNIÈRE; BOUQUIN 2014, p. 189), contribuiu para que, no século seguinte, inúmeras revistas científicas existentes acabassem servindo de forma mais eficiente para a divulgação da avolumada pesquisa universitária, que não poderia mais esperar pela publicação do longo e demorado livro autoral. Os pesquisadores buscavam uma forma rápida de divulgação da pesquisa científica e encontraram nos periódicos o lugar ideal para isso. As revistas científicas foram, então, concentrando boa parte da produção historiográfica e tornaram-se espaços importantes para compreender os caminhos percorridos pela historiografia (BENTIVOGLIO 2017, p. 7-11).

Este artigo tem como principal objetivo promover um balanço editorial e de publicações dos dez anos de existência do periódico científico História da Historiografia, publicação quadrimestral da Sociedade Brasileira de Teoria e História da Historiografia (SBTHH), do Programa de Pós-Graduação em História da Universidade Federal do Estado do Rio de Janeiro (UNIRIO) e do Programa de Pós-Graduação em História da Universidade Federal de Ouro Preto (UFOP).

A História da Historiografia tem como principal missão "tornar-se um fórum de excelência no âmbito das subdisciplinas que constituem seu foco e que são sua razão de ser" (OS EDITORES 2010b, p. 10), quais sejam, a história da historiografia e a teoria da história. Iniciativas anteriores como a criação do Núcleo de Estudos em História da Historiografia e 
Modernidade (NEHM), do Departamento de História da UFOP, e o que viria a ser a primeira edição do Seminário Brasileiro de Teoria e História da Historiografia (SNHH), ambas em 2007, foram decisivas para a viabilização da revista. Em 2009, houve a criação da SBTHH, entidade representativa do setor de história da historiografia e teoria da história no Brasil. Índice do desenvolvimento do campo são também os periódicos Revista de Teoria da História, fundada em 2009, e Expedições: Teoria da História e Historiografia, fundado em 2010. Certamente a ampliação desses dois campos de pesquisa no Brasil não é um fenômeno do século XXI. Um pouco mais distante do contexto atual, mas não menos importante, foi o trabalho desenvolvido por José Honório Rodrigues entre as décadas de 1940 e 1960 (OLIVEIRA; GONTIJO 2016, p. 16). As pesquisas realizadas a partir da década de 1970 foram de extrema importância para o desenvolvimento da história da historiografia e da teoria da história na medida em que os pesquisadores atuantes ocuparam postos em diversas universidades brasileiras e, com suas pesquisas e orientações, ajudaram a formar 0 campo que viria a se consolidar posteriormente (NICODEMO; SANTOS; PEREIRA 2018, p. 35-36). A fundação da História da Historiografia, como aconteceu com outros periódicos (ROCHA 2018, p. 39), parece marcar a consolidação de um campo de pesquisa, com pesquisadores dispostos a manter um espaço coletivo de diálogo disciplinar.

A revista História da Historiografia é talvez a primeira revista de história brasileira a adotar, desde seu surgimento, um perfil editorial de publicação altamente especializado, aspecto que vem sendo valorizado pelo Conselho Nacional de Desenvolvimento Científico e Tecnológico (CNPq) e pela Coordenação de Aperfeiçoamento de Pessoal de Nível Superior (CAPES) (SILVEIRA; BENEDET; SANTILLÁN-ALDANA 2018, p. 98), sendo uma das ações decisivas para a visibilidade das pesquisas produzidas dentro de suas principais temáticas: a história da historiografia e a teoria da história. O periódico lançou seu primeiro número no final de 2008 , em uma época em que havia um constante questionamento sobre a viabilidade financeira e 
visibilidade das revistas impressas. Utilizando o Sistema Eletrônico de Editoração de Revistas (SEER) desde 2009, a revista nasceu exclusivamente eletrônica em um momento de expansão da plataforma. Segundo o Instituto Brasileiro de Informação em Ciência e Tecnologia (IBICT), em 2009, 800 periódicos científicos brasileiros usavam o SEER (FERREIRA; CAREGNATO 2008), ${ }^{1}$ número que mais que dobrou nos últimos anos.

O surgimento da História da Historiografia está ligado ao desejo de um grupo de pesquisadores sediados em várias universidades brasileiras de consolidar o campo da história da historiografia e da teoria da história no Brasil. Na contramão de uma das características marcantes dos periódicos brasileiros, a revista sempre se apresentou como uma iniciativa interinstitucional. No início de sua existência, a pluralidade institucional do periódico era garantida pela variedade dos integrantes de seu Conselho Executivo e Editorial, situação que foi mudando, na medida em que a revista ganhou apoio direto de algumas instituições. Desde 2010, a História da Historiografia passou a ser oficialmente uma publicação da SBTHH, visando reforçar o modelo de gestão de periódico interinstitucional e altamente especializado adotado desde a sua fundação (OS EDITORES 2010c, p. 10).

É difícil precisar em que momento a revista viu-se vinculada também a dois programas de pós- graduação - UFOP e UNIRIO -, mas isso parece ter acontecido poucos anos após a sua fundação. Nos primeiros números da revista constam como patrocinadores o Instituto de Filosofia e Ciências Humanas, da Universidade Federal do Rio Grande do Sul (UFRGS), o NEHM da UFOP e o Programa de Pós-graduação em História da UFOP. A primeira vez que os programas de pós-graduação, assim como a SBTHH, aparecem de forma oficial nos créditos da História da Historiografia é no número 6, de 2011. Na seção "Promoção", nos créditos da revista, figuram os nomes da SBTHH e dos Programas de Pós-Graduação em História da UNIRIO, UFRGS e UFOP. No número seguinte, há nova configuração, adotada até hoje, na qual compõem a seção "Realização" a SBTHH e
1 - O SEER é uma customização feita pelo IBICT, em 2003, do Open Journal Systems (OJS), desenvolvido pelo Public Knowledge Project (PKP) desde a década de 1990. A primeira revista brasileira a utilizar o SEER foi a Ciência da Informação, do IBICT, em 2004. http://www. ibict.br/pesquisa-desenvolvimento-tecnologico-e-inovacao/ sistema-eletronico-de-editoracao-de-revistas-seer/historico e https://pkp.sfu.ca/ ojs/ojs-usage/ojs-map/. 
os Programas de Pós-Graduação em História da UNIRIO e da UFOP. $^{2}$

Em sua primeira avaliação no Qualis, em 2010, a História da Historiografia alcançou a nota B2 na área de História. Em 2012, foi avaliada como Qualis B1 (ASSIS; BENTIVOGLIO; GONTIJO 2012, p. 9) e no ano seguinte como Qualis A1 (ASSIS; BENTIVOGLIO; GONTIJO 2013, p. 8). A classificação dentro do Qualis Periódico, sistema de avaliação de periódicos que possuem artigos de pesquisadores vinculados a programas de pós-graduação brasileiros, gerido pela CAPES, é um aspecto definidor de toda revista científica brasileira e motivo de grande preocupação de seus editores. Em apenas cinco anos de existência a História da Historiografia entrou para o seleto grupo de periódicos avaliados como de alto impacto pela CAPES, contribuindo para maior visibilidade das pesquisas desenvolvidas em história da historiografia e teoria da história.

$\mathrm{Na}$ avaliação das revistas mais antigas, um elemento central era o tamanho de sua tiragem, que indicava a circulação do periódico. Atualmente, em um contexto de abandono progressivo do meio impresso pelos editores científicos, surgiram novos mecanismos para avaliar o impacto das revistas, medido através de índices bibliométricos. Nas décadas de 1990 e 2000, surgiram mecanismos importantes de mensuração da qualidade dos periódicos científicos em âmbito internacional, tais como o Web of Science, da Clarivate Analytics, e o Scopus, da Elsevier. Em 2013, a revista História da Historiografia foi aceita na base de dados Scopus, sendo possível calcular desde essa data a influência do periódico através da média do número de citações obtidas. Seguindo as normativas internacionais de gestão de conteúdo eletrônico, em 2014, o periódico passou a adotar Digital Object Identifier (DOI), sequência numérica única de identificação de conteúdos digitais, em todas as suas publicações (OS EDITORES 2014, p. 8).

Aliado ao reconhecimento obtido pela qualidade dos artigos publicados e consistência do projeto editorial, a revista também recebeu diversos financiamentos oriundos de projetos de apoio
2 - Os números 25, 2017 e 26, 2018 não possuem edição completa para visualização na página da revista, sendo impossível conferir se as informações são mantidas conforme descrito também nesses números. 
à editoração de periódicos do CNPq, da Fundação de Amparo à Pesquisa do Estado de Minas Gerais (FAPEMIG), da Fundação Carlos Chagas Filho de Amparo à Pesquisa do Estado do Rio de Janeiro (FAPERJ) e do Instituto de Pesquisa Econômica Aplicada (IPEA), que contribuíram para a sua consolidação. No Brasil, a grande maioria das revistas da área de História é mantida com verba dos programas de pós-graduação às quais são vinculadas, por editais de fomento e, mais recentemente, por campanhas de financiamento coletivo. Tem sido um grande esforço das instituições científicas e universitárias brasileiras manter a política de acesso aberto a todo o conteúdo de seus periódicos, chancelada por diversos editais de financiamento federais e estaduais. Por outro lado, há uma pressão para que os periódicos sejam indexados nas bases de dados de grandes editoras comerciais reconhecidas mundialmente, como o Web of Science e Scopus, que se choca com o modelo de acesso livre e gratuito do conhecimento científico brasileiro (SILVEIRA; BENEDET; SANTILLÁN-ALDANA 2018, p. 93-94).

Os editores da História da Historiografia, não de hoje, enxergavam a potencialidade que a revista possuía como testemunha da expansão dos campos de pesquisa da história da historiografia e da teoria da história no Brasil (ASSIS; BENTIVOGLIO; GONTIJO 2011, p. 9). É esse potencial que gostaria de explorar ao longo deste artigo, no intuito de, através da análise de diversas variáveis, lançar o que pode ser tido como o primeiro esforço de análise da produção científica dentro do periódico. Foram reunidos e analisados 285 artigos enviados por 271 colaboradores, publicados durante os dez anos de existência do periódico, com o objetivo de conhecer melhor o campo da história da historiografia e da teoria da história no Brasil nas primeiras décadas do século XXI. Com esse intuito em vista, buscou-se identificar os principais autores, períodos, países e temas estudados; filiações institucionais, países, regiões e idiomas em evidência; percentagem de financiamento das pesquisas e órgãos de fomento, além de trazer à tona a questão de gênero e cor ou raça. $O$ objetivo principal foi traçar uma radiografia do campo a partir de "[...] 
um dos mais significativos loci editoriais da discussão teóricohistoriográfica no cenário brasileiro" (ASSIS; BENTIVOGLIO; GONTIJO 2011, p. 9).

\section{Análise do perfil dos editores executivos da História da Historiografia}

De forma geral, houve uma tendência das revistas científicas brasileiras em História de serem vinculadas a um programa de pós-graduação, principalmente as mais antigas, que foram criadas dentro do contexto de expansão da pósgraduação brasileira na década de 1980, com o intuito de dar visibilidade entre os pares para as pesquisas produzidas. Inspirada em periódicos profundamente especializados, tais como a History and Theory e a Storia della Storiografia, a História da Historiografia buscou, através da valorização da diversidade institucional de seu conselho dirigente, promover desde a sua fundação um novo modelo de gestão editorial que apostava na interinstitucionalidade (ASSIS; BENTIVOGLIO; GONTIJO 2011, p. 9).

A estrutura administrativa da revista variou pouquíssimo ao longo desses primeiros dez anos. Em um momento inicial, a revista contava com um Conselho Editorial enxuto: Helena Mollo, da UFOP, Pedro Spinola Pereira Caldas, então professor na Universidade Federal de Uberlândia (UFU), Sérgio da Mata, da UFOP, Temístocles Cezar, da UFRGS, e Valdei Lopes de Araujo, da UFOP. Logo em 2009, em seu terceiro número, aparece uma nova estrutura administrativa da revista, denominada Conselho Executivo, que abrigava Pedro Spinola Pereira Caldas, já professor na UNIRIO, Sérgio da Mata e Valdei Lopes de Araujo, membros do Conselho Editorial fundador. Aliado a isso, houve forte expansão do Conselho Editorial, que teve suas atividades circunscritas à manutenção do projeto editorial, permanência e qualidade da revista, enquanto que o Conselho Executivo ficou com a missão de cuidar dos aspectos administrativos diários do periódico. Ao término do mandato de dois anos, os editores 
executivos passariam a integrar o Conselho Editorial como membros vitalícios.

O compromisso com um modelo de gestão de periódico interinstitucional foi sendo renovado a cada gestão. Entre 2011 e 2013, dividiram a editoria executiva da revista Arthur Alfaix Assis (Universidade de Brasília), Julio Bentivoglio (Universidade Federal do Espírito Santo) e Rebeca Gontijo (Universidade Federal Rural do Rio de Janeiro). No número 13, de dezembro de 2013, o Conselho Executivo incorpora o seu primeiro pesquisador externo à comunidade acadêmica brasileira, constando nesse Conselho, além de Arthur Alfaix Assis, Rebeca Gontijo e Rodrigo Turin (UNIRIO), o nome do argentino Fabio Wasserman (Universidad de Buenos Aires). No número seguinte, há nova mudança com a saída de Arthur Assis e a entrada de Fernando Nicolazzi (UFRGS) e Helena Mollo (UFOP). A transição entre os conselheiros é finalizada na edição de número 15 , de agosto de 2014, com a saída de Rebeca Gontijo. Uma próxima mudança na direção da revista ocorre na edição 21 , de agosto de 2016, onde assumem a editoria junto de Mollo, Alejandro Eujanian (Universidad Nacional de Rosario - Argentina), Arthur Lima de Ávila (UFRGS) e Fábio Franzini (Universidade Federal do Estado de São Paulo). O Conselho Executivo sofreu sua última reformulação na edição 25, de dezembro de 2017, com a saída de Mollo e a entrada de Mateus Henrique Faria Pereira (UFOP) e Valdei Lopes de Araujo.
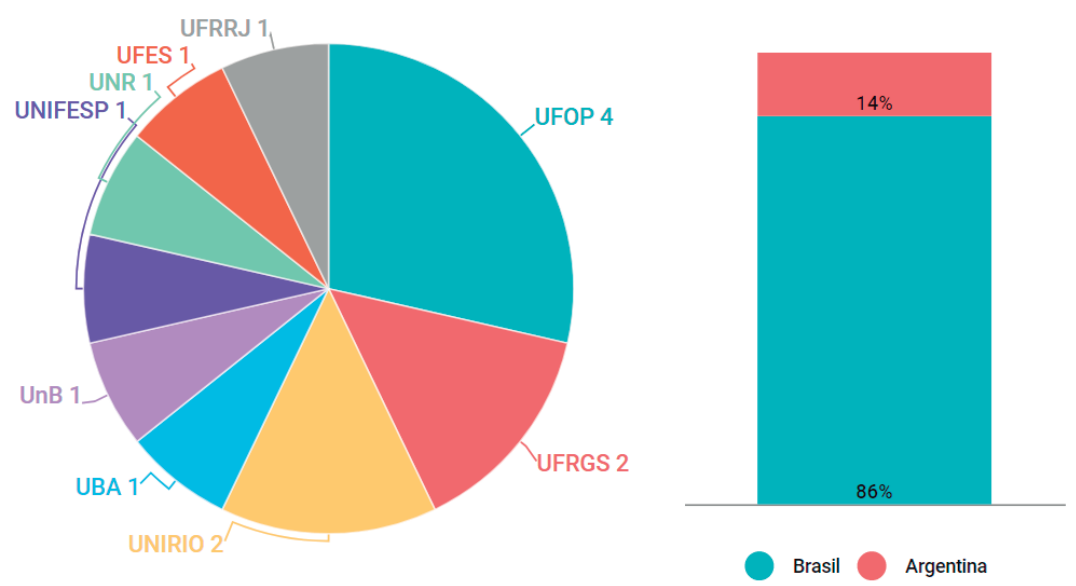

Gráfico 1 - Composição do Conselho Executivo, dividida por universidade e país 
Asistematização dos dados referentes aos diversos conselhos executivos da revista permite confirmar a proposta inicial da História da Historiografia de se manter como um periódico interinstitucional, com tendência discreta à internacionalização de seu Conselho Executivo. Não obstante esse processo, analisando a diversidade regional dos pesquisadores brasileiros vinculados ao Conselho Executivo, obtém-se que $75 \%$ deles estão vinculados a instituições do sudeste, $17 \%$ do sul e $8 \%$ do centro-oeste do Brasil. Nesses dez anos de existência, a História da Historiografia nunca contou com nem um pesquisador do norte ou do nordeste em seu Conselho Executivo, mesmo tendo contado com pesquisadores dessas regiões como autores de artigos, conforme Gráfico 12.

A despeito da diversidade e variedade institucional dos membros do Conselho Executivo, chama atenção a presença mais forte de pesquisadores vinculados à UFOP, UNIRIO e UFRGS, conforme o Gráfico 1. Dentre os 14 editores do periódico, 4 são da UFOP (29\%), 2 da UNIRIO (14\%) e 2 da UFRGS (14\%). Índice da centralidade da UFOP, instituição com maior número de pesquisadores no Conselho Executivo, na História da Historiografia é a permanência por quase quatro anos de Helena Mollo e a participação por duas vezes de Valdei Araujo na gestão do periódico. Casos desse tipo só foram identificados em relação a essa Universidade. De qualquer forma, a importância dessas três instituições deve-se não só ao fato de que todos os membros do Conselho Editorial fundador são vinculados a elas, mas também ao atrelamento da revista a alguns de seus programas de pós-graduação existentes, que contribuíram financeiramente no pagamento de despesas corriqueiras do periódico, como diagramação e revisão.

Tendo em vista que, na atual conjuntura brasileira, a concorrência em editais de financiamento é impossível aos projetos editoriais iniciais, em que apenas revistas indexadas em bases de dados internacionais de difícil acesso podem concorrer, esses projetos precisam ser custeados de outra forma. A hospedagem do site da História da Historiografia, 
por exemplo, essencial para uma revista que surgiu como exclusivamente eletrônica, até 2013, era feita no servidor da UFOP sob o domínio www.ichs.ufop.br/rhh, e o e-mail também era institucional da UFOP, o historiografia@ufop.br. Como salientado anteriormente, em vários números iniciais da História da Historiografia, tanto a UFOP quanto a UFRGS aparecem como contribuindo financeiramente em algum nível. Em fase posterior, os créditos da revista apontam que pesquisadores da UNIRIO coordenaram por duas vezes projetos de apoio à publicação de periódicos da FAPERJ, assim como pesquisadores da UFOP coordenaram por três vezes projetos de apoio à publicação de periódicos fomentados pela FAPEMIG. Não obstante a História da Historiografia certamente ser um projeto interinstitucional, sua formação parece estar ligada a um núcleo de pesquisadores situados na UFOP, UNIRIO e UFRGS.

Em um contexto em que a visibilidade e importância das questões ligadas ao gênero permitem repensar alguns pressupostos do próprio campo da história da historiografia e da teoria da história, não poderíamos deixar de quantificar a presença de pesquisadores e pesquisadoras no Conselho Executivo da História da Historiografia.

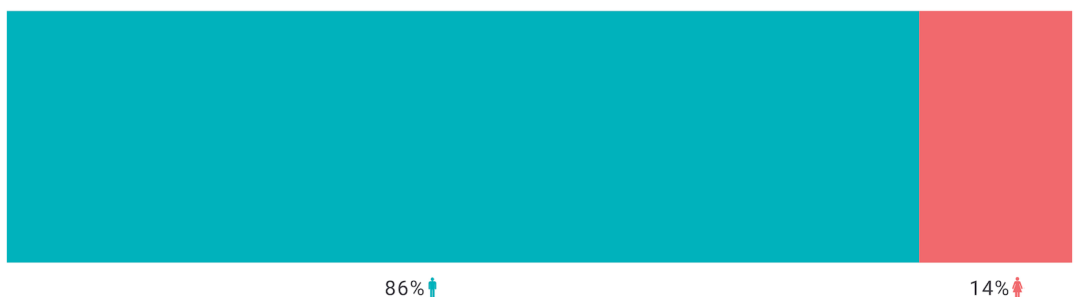

Gráfico 2 - Percentual de editores executivos segundo o sexo

Dentre os 14 pesquisadores que ocuparam o posto da editoria executiva do periódico, 12 deles são homens (86\%) e 2 deles são mulheres (14\%). É necessário frisar, contudo, que as editoras tiveram tendência a permanecer por mais tempo do que os dois anos de atuação corriqueiros. Helena Mollo, como colocado, foi editora da História da Historiografia por quase quatro anos, e Rebeca Gontijo por quase dois anos e meio.

A disparidade encontrada no Conselho Consultivo não é um 
traço da área de História ou do campo da história da historiografia e teoria da história. Segundo a listagem de pesquisadores com Bolsa de Produtividade em Pesquisa - PQ disponibilizada no site do $\mathrm{CNPq}$, dos 249 pesquisadores contemplados na área de História em alguma das modalidades, 138 (55\%) são do sexo masculino e 111 (45\%) do sexo feminino. ${ }^{3}$ Tendo em vista a razoável proporcionalidade de gênero entre pesquisadores que possuem produção de destaque em História, é notável o hiato de gênero no Conselho Executivo da História da Historiografia. A baixa participação feminina no Conselho Executivo da revista, contudo, não se deve à concentração de homens na área de especialização do periódico, visto que a totalidade dos sócios da SBTHH, em 2018, estava dividida entre $60 \%$ de homens e $40 \%$ de mulheres, número muito mais equilibrado do que o visto no periódico. Atualmente existem quatro tipos de categoria de filiação à SBTHH: graduandos, graduado, pós-graduandos e professores universitários. Restringindo os dados da pesquisa exclusivamente aos professores universitários, que estariam qualificados a assumir a editoria da revista, o percentual obtido é bastante próximo ao visto dentre todos os sócios: $62 \%$ são do sexo masculino e $38 \%$ são do sexo feminino.

Outro tema igualmente importante no ambiente científico brasileiro diz respeito à desigualdade racial entre o número de universitários, sejam discentes ou docentes. Reconhecendo a complexidade que envolve a identificação racial, optou-se por empregar o aprimorado sistema classificatório de "cor ou raça" do Instituto Brasileiro de Geografia e Estatística (IBGE). Foi enviado um questionário com uma única pergunta a todos os pesquisadores que fizeram parte do Conselho Executivo da História da Historiografia. Nele perguntava-se a mesma questão realizada no Censo 2016 pelo IBGE: a sua cor ou raça é? Utilizou-se como referência para a autoclassificação as cinco categorias empregadas pelo Instituto, nessa ordem: branca, preta, amarela, parda e indígena.

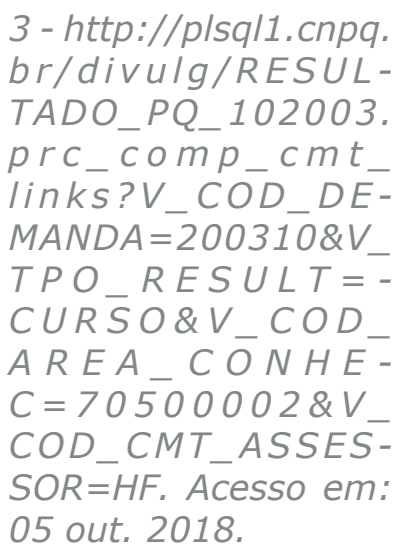

3 - http://plsql1.cnpq. br/divulg/RESUL TADO_PQ_102003. prC_COMP_Cmt links? V_COD_DE$M A N D A=200310 \& V$ $T P O_{-} R E S U L T=-$ CURSO\&V_COD $A R E A-C O N H E-$ $C=70500002 \& V_{-}$ COD_CMT_ASSES05 out. 2018. 


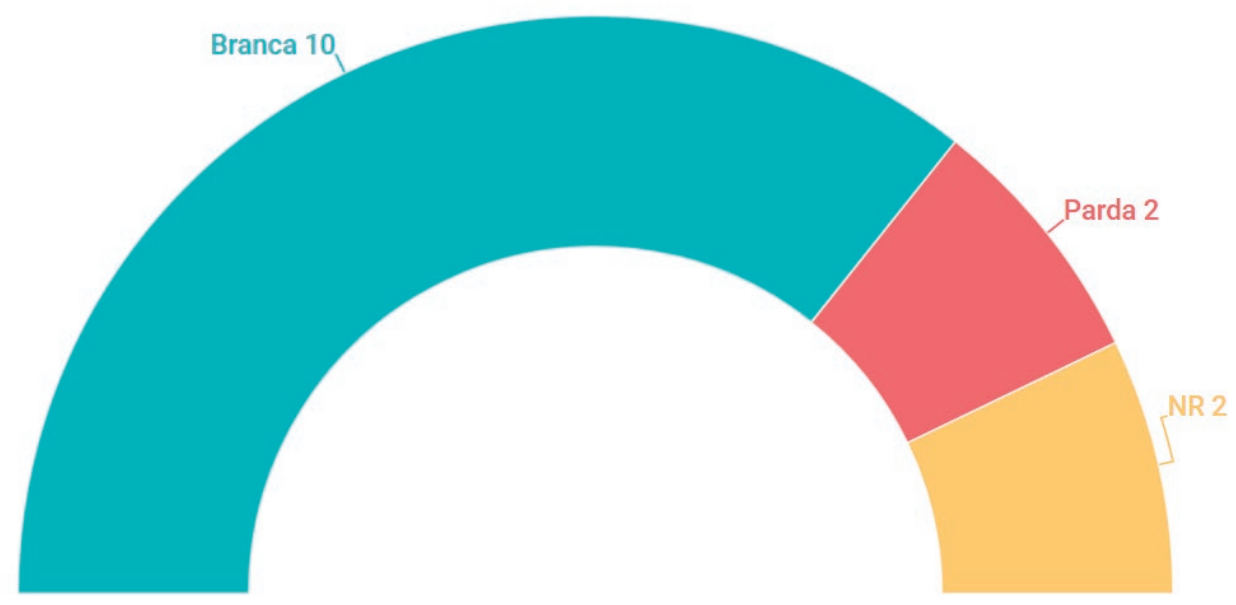

Gráfico 3 - Número de editores executivos segundo raça ou cor

Dos 14 editores executivos que atuaram na História da Historiografia, 10 deles se autoclassificaram como brancos ( $72 \%$ ) e 2 como pardos (14\%), sendo que dois editores (14\%) não responderam a pergunta. De acordo com os microdados do Censo da Educação Superior de 2017, realizado pelo Instituto Nacional de Estudos e Pesquisas Educacionais Anísio Teixeira (INEP), a porcentagem de professores do magistério superior que se autodeclararam brancos foi de $53,6 \%$, negros de $16 \%$ - sendo $1,8 \%$ de negros e $14 \%$ de pardos - amarelos de $1 \%$ e indígenas de $0,1 \%$. É importante salientar o alto nível de recusa à autoclassificação ao questionário do INEP. 29,4\% do total de professores entrevistados se recusaram a declarar cor ou raça, provavelmente externando o desejo de não dar cor à ciência brasileira (MORENO 2018). A comparação dos dados disponibilizados pelo INEP, na ausência de bases de dados mais específicas de amplo acesso, nos permite concluir, mesmo que provisoriamente, que o percentual de editores executivos da História da Historiografia espelha as assimetrias do sistema universitário no que concerne à raça ou cor, sendo que, no que diz respeito ao gênero, a disparidade está muito mais acentuada, inclusive se comparada com o levantamento do INEP que também apresenta $45,5 \%$ dos docentes do magistério superior sendo do sexo feminino (MORENO 2018). Nota-se, contudo, que nem um pesquisador negro, amarelo ou indígena fez parte do Conselho Executivo do periódico. 
Obviamente que decidir quem fará parte da editoria executiva de um periódico não é uma tarefa burocrática. Além do capital humano disponível, simples fatores como disponibilidade e interesse em assumir a função são centrais. O processo de escolha dos membros do Conselho Executivo é multifacetado e envolve a participação de seus integrantes, que podem ser reconduzidos, das redes imaginadas e a chancela do Conselho Editorial.

\section{Análise do perfil dos artigos publicados na História da Historiografia}

Originalmente lançada como uma revista semestral, a História da Historiografia alterou a sua periodicidade em 2012, passando a publicar três números por ano no intuito de abrigar a crescente produção na área (ASSIS; BENTIVOGLIO; GONTIJO 2012, p. 8). Conforme podemos ver no Gráfico 4, havia represamento de demanda, pois, nos anos subsequentes, a mudança de periodicidade o periódico continuou publicando um volume de textos muito próximo ou superior às edições anteriores:

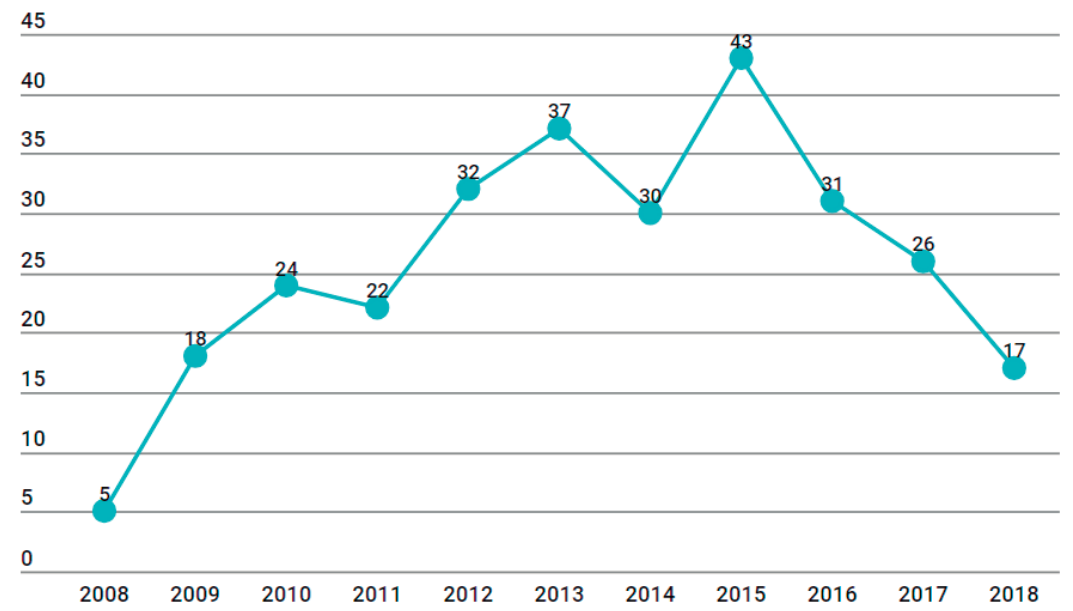

Gráfico 4 - Quantidade de artigos publicados

Verificou-se, pelo Gráfico 4, que, levando em consideração a mudança na periodicidade, o maior número de artigos publicados foi em 2015, puxado pelas edições 17 e 18, perfazendo um total 
de 43 artigos, ou seja, $15 \%$ do total dos artigos analisados. A edição 17 foi a edição com maior número de artigos nos dez anos de publicação do periódico, contando com 15 artigos publicados na seção livre; e 4 no caderno especial. O menor número de artigos publicados por número, descartando-se o primeiro ano da revista e o último, que não tiveram séries completas, foi em 2017. Em 2008, a revista publicou 5 artigos por número; em 2009, publicou 9 artigos por número; em 2010, publicou 12 artigos por número; em 2011, publicou 11 artigos por número; em 2012, publicou 10,6 artigos por número; em 2013, publicou 12,3 artigos por número; em 2014, publicou 10 artigos por número; em 2015, publicou 14,3 artigos por número; em 2016, publicou 10,3 artigos por número; em 2017, publicou 8,66 artigos por número; e, em 2018, publicou 8,5 artigos por número. Observa-se que o número de artigos publicados na revista, desde a sua fundação, veio crescendo com certa estabilidade até 2015, com ligeira queda em 2014, mas que após esse ano ao periódico publicou menos artigos por número, chegando atualmente a um patamar muito próximo da quantidade de artigos que publicava por número em seu segundo ano de existência.

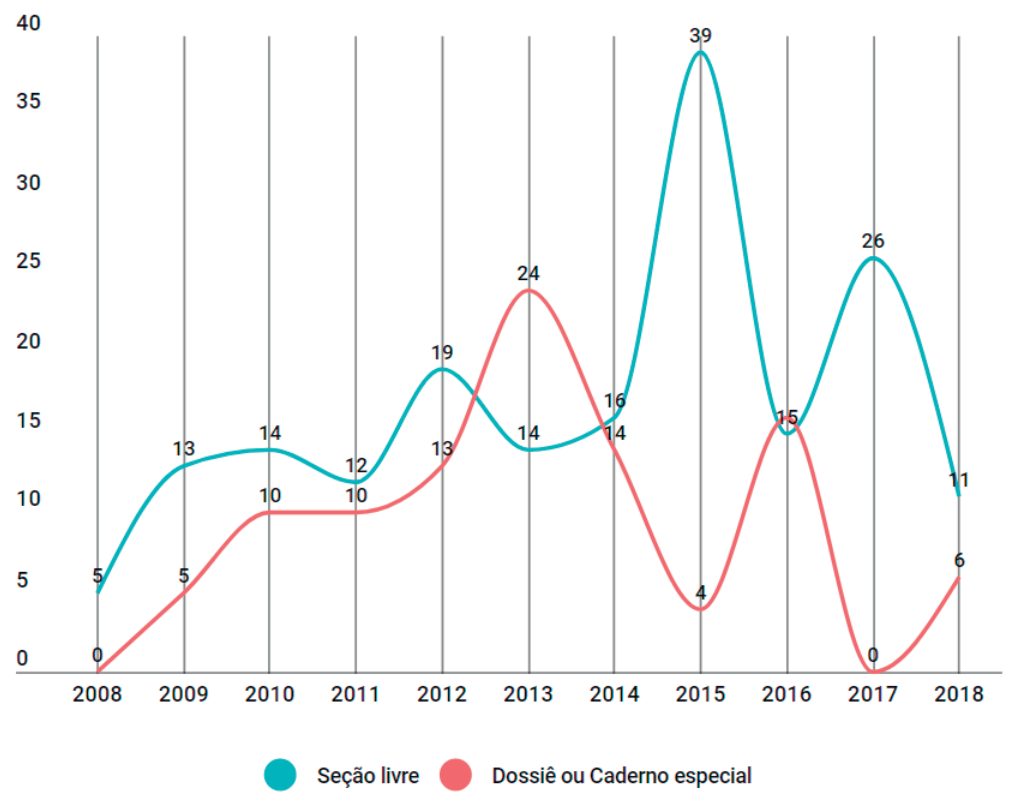

Gráfico 5 - Comparação entre o número de artigos publicados na seção livre e em dossiê ou caderno especial 
"Da Monarquia à República: questões sobre a escrita da história" foi o primeiro dossiê, lançando no segundo número da História da Historiografia, de março de 2009, organizado pelo então professor do Departamento de História da UFOP, Fernando Nicolazzi. Em 2011, os editores passaram a adotar uma chamada aberta de artigos para essa seção e as publicações deixaram de ser estritamente compostas por convidados (ASSIS; BENTIVOGLIO; GONTIJO 2011, p. 9). Contudo, os organizadores dos dossiês continuaram sendo convidados pela equipe editorial, sendo que, em 2018, adotouse a chamada aberta para proposição de dossiês. Ao longo dos seus dez anos de existência, o periódico publicou 14 dossiês sobre os mais variados temas e um caderno especial, que reuniu parte das conferências apresentadas no $6^{\circ}$ Seminário Brasileiro de História da Historiografia (SNHH). Exceto pelos números lançados em 2015 e 2017, percebe-se que a quantidade de artigos publicadas na seção dossiê ou caderno especial configuraram parte significativa dos artigos presentes na História da Historiografia. Em 2013, o número de artigos publicados em dossiê chega mesmo a ultrapassar o número de artigos na seção livre do periódico, conforme o Gráfico 5.

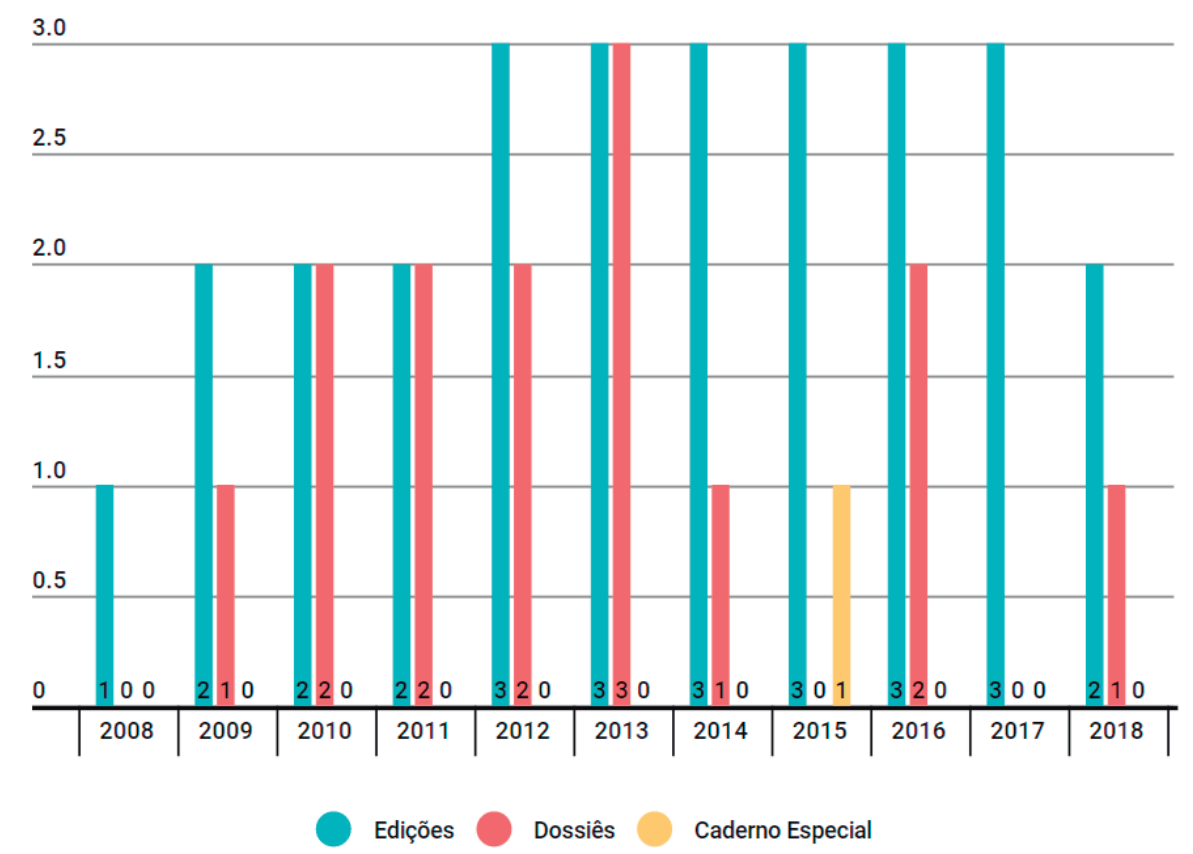

Gráfico 6 - Comparação entre o número de edições, dossiês e caderno especial 
Com relação à regularidade dos dossiês e caderno especial, como demonstra o Gráfico 6, não é possível estabelecer nenhuma política editorial coerente em relação aos números temáticos da revista, não obstante ter sido almejado pelos editores publicar um dossiê no último número de cada ano, a partir de 2014 (MIRANDA 2013, p. 9). A proposta não foi concretizada, já que em 2015 nem um dossiê foi publicado pela revista - na primeira edição do ano houve a publicação de um Caderno Especial -, no ano seguinte foram publicados dois dossiês (edição 20 e 22); em 2017, nem um dossiê foi publicado e, em 2018, um dossiê foi publicado na segunda edição do ano. De qualquer forma, observa-se que o periódico abandonou a prática vigente entre os anos de 2010 e 2011 de ter em todos os seus números um dossiê temático, não deixando de lado o estímulo ao debate mais verticalizado e pautando as discussões no campo. É importante destacar o dossiê "Teoria da história da historiografia", publicado na edição 12, de 2013, em que se buscou fomentar a discussão sobre o significado e abrangência da subdisciplina que dá nome ao periódico, formato parecido com o que foi feito nos números iniciais da Storia della Storiografia (NICODEMO; SANTOS; PEREIRA 2018, p. 21).

\section{Perfil dos autores}

A História da Historiografia propôs desde a sua fundação construir-se como um "espaço democrático de discussão teórica e metodológica sobre a história, onde o que importa não é a idade ou a titulação dos autores, mas a qualidade do artigo, da resenha, do documento comentado" (CEZAR 2014, p. 8). Em sintonia com essa perspectiva, a revista nunca adotou nenhuma restrição em suas normas editorias quanto à titulação de seus colaboradores. Não obstante o estímulo ao debate horizontal e aberto, observa-se pouca representatividade de alunos da graduação e de mestrado na seção artigo, conforme o Gráfico 7. 


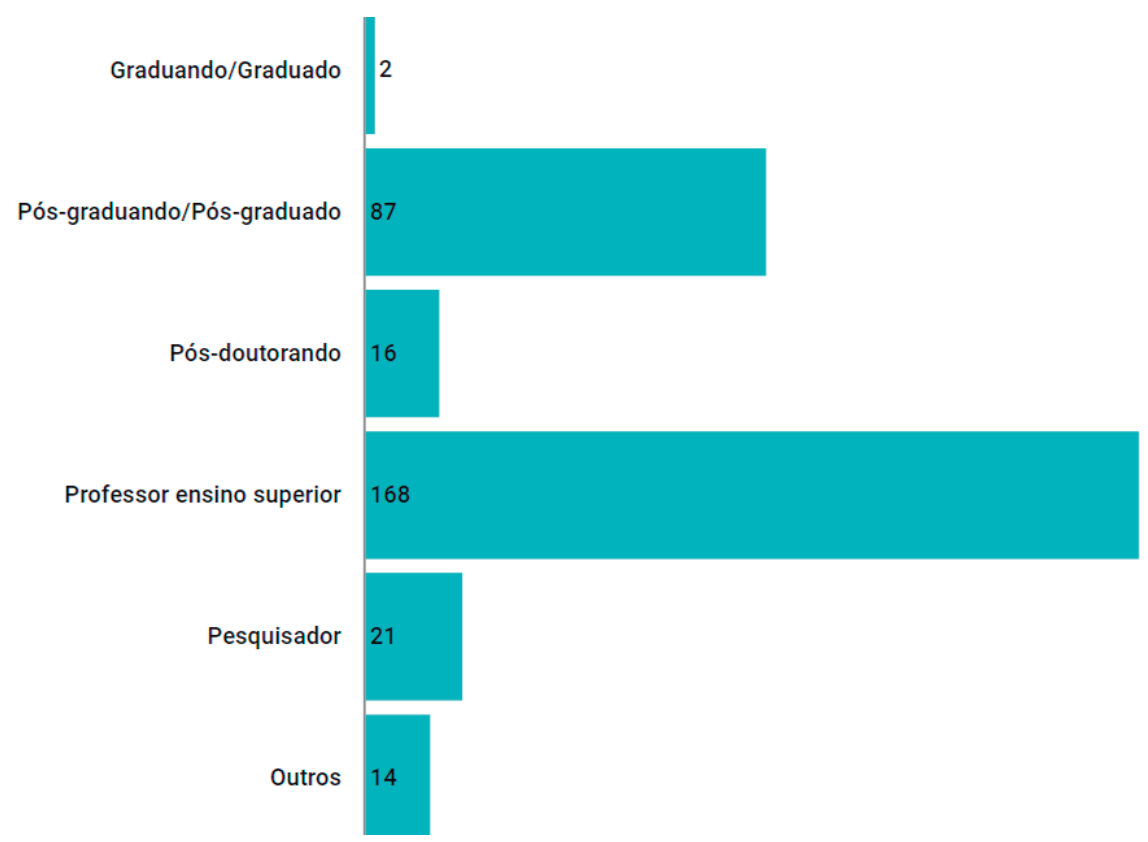

Gráfico 7 - Número de autores de artigos segundo a situação acadêmica

Em relação à graduação, dentre os 308 autores, ${ }^{4}$ um declarou-se graduado em História, na edição de 2009, e uma graduanda, em coautoria com o orientador, em 2011. Na pósgraduação, tem-se 10 mestrandos e 11 mestres como autores, ou seja, $7 \%$ do conteúdo publicado na seção artigo é oriundo de pesquisadores no primeiro estágio da especialização. É indiscutível, porém, que mesmo essa modesta representação, atualmente, é raríssimas vezes encontrada em revistas nacionais e internacionais em alto estrato, que tendem a descartar de antemão trabalhos de pesquisadores sem doutorado. Dividindo a situação acadêmica dos autores em grandes blocos, a maior quantidade de autores na História da Historiografia é de professores do ensino superior, 158 autores (55\%); seguido de pós-graduandos ou pós-graduados, 87 autores (28\%); e de pesquisadores, 21 autores (7\%).

4 - Optou-se por não excluir da contagem a segunda, terceira ou quarta aparição do mesmo autor. 


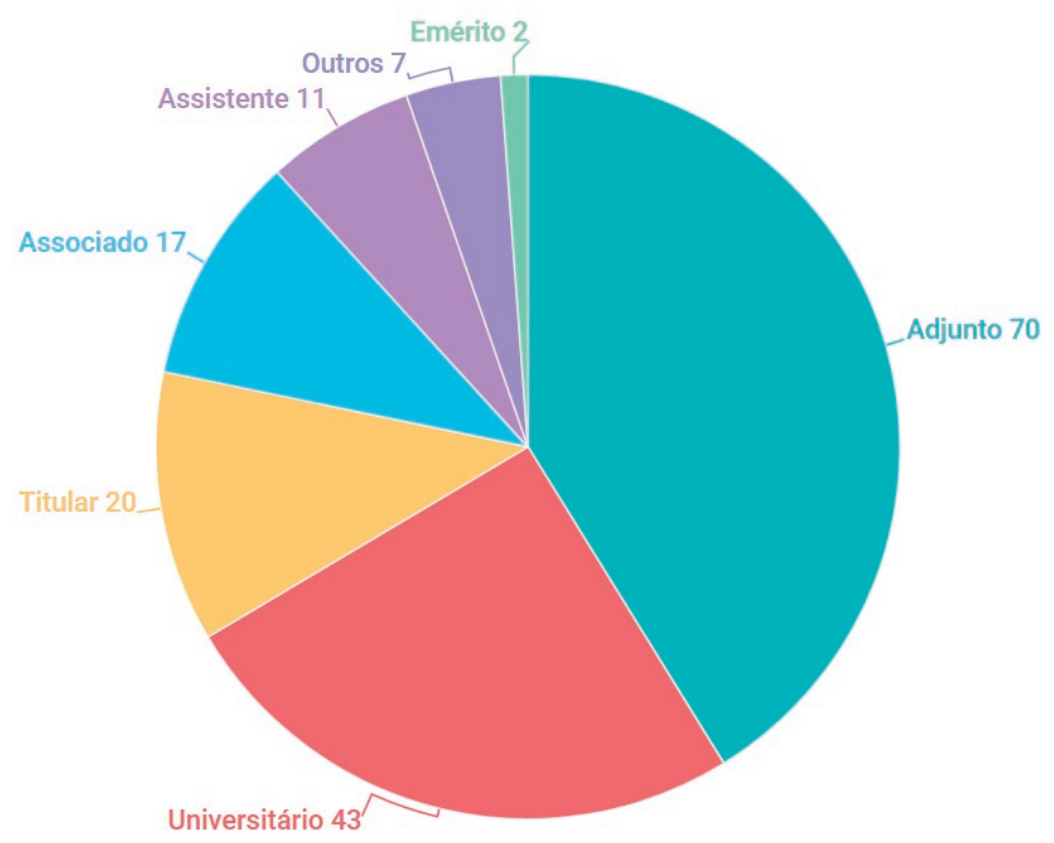

Gráfico 8 - Professores do ensino superior segundo as etapas da progressão da carreira

Dentre os professores do ensino superior, os que mais publicaram na revista foram professores adjuntos, com 70 publicações (41\%), seguidos dos professores titulares, com 20 publicações (12\%) e associados, com 17 publicações (10\%). Houve um alto índice de pessoas que não especificaram a sua situação acadêmica dentro da universidade e que foram classificadas como professores universitários e somaram 43 autores (25\%). No conjunto de seus autores, a revista reflete a novidade da própria área, ao ter como principais colaboradores professores universitários no estágio inicial da carreira.

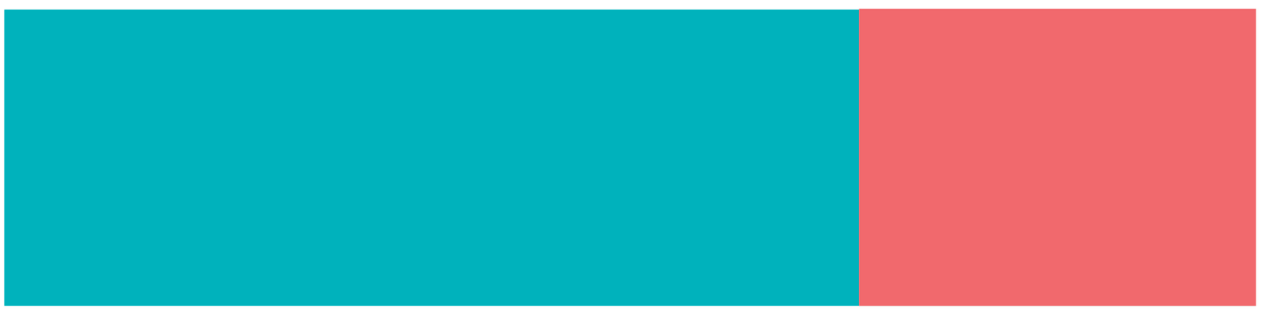

$68 \%$ 
Realizando a classificação dos autores de artigos segundo o sexo, observou-se menor discrepância do que o visto em relação ao Gráfico 2, que mostrava o percentual de editores executivos segundo o sexo, apesar de, mesmo assim, haver preponderância de pesquisas desenvolvidas por homens. No conjunto de todos os autores, 208 deles são do sexo masculino (68\%) e 100 deles são do sexo feminino (32\%). Os autores são um pouco mais do que o dobro das autoras de artigos, sintoma também da longa tradição brasileira de baixa representatividade feminina em periódicos. Na Revista do Instituto Histórico e Geográfico Brasileiro, um dos periódicos mais importantes na área de História durante muito tempo, não houve nem uma publicação de pena feminina durante todo o século XIX. Essa situação muda, ainda que discretamente, com a reforma universitária nas primeiras décadas do século XX (BENTIVOGLIO 2017, p. 13).

\section{Perfil das instituiçōes}

Os periódicos científicos do século XXI são sensivelmente distintos de seus ancestrais, devido a mudanças tecnológicas e profissionais no campo da editoria científica. No que diz respeito ao contexto de desenvolvimento editorial em que os periódicos brasileiros estão inseridos, estaríamos em uma época em que a internacionalização apresenta-se como o grande desafio aos editores. Fazendo um rápido e esquemático retrospecto, entre as décadas de 1980 e 1990, os periódicos brasileiros estavam em fase de normalização, em que havia certa instabilidade no fluxo e nas práticas editoriais. As próximas décadas teriam visto um processo de consolidação dos periódicos, fruto do maior apoio governamental e da maior profissionalização de sua equipe de gerência. A partir dessas ondas que ajudaram a normatizar e consolidar a prática editorial científica brasileira, desde 2015 o grande desafio dos periódicos vem sendo a internacionalização da produção e colaboração científica, em 
sintonia também com a expansão do acesso livre à informação como valor científico (ALPERIN; ROZEMBLUM 2017 apud SILVEIRA; BENEDET; SANTILLÁN-ALDANA 2018, p. 92-93).

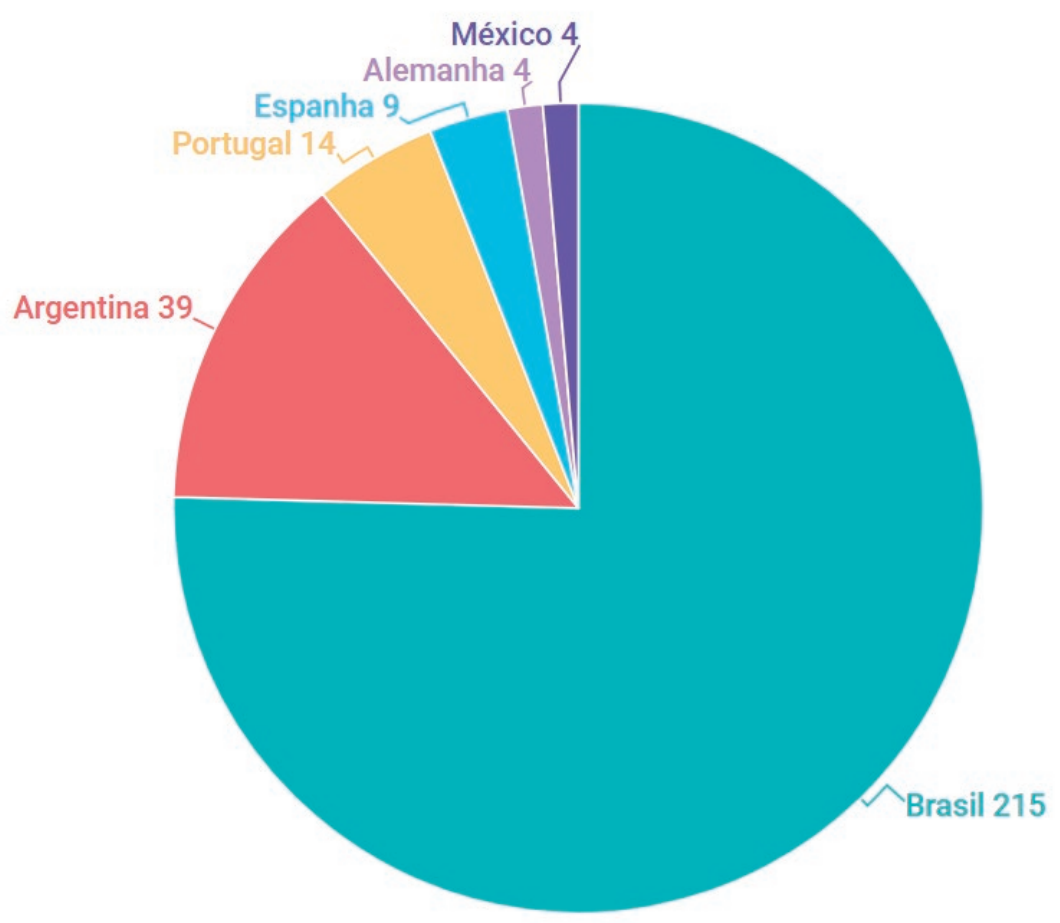

Sem nenhuma surpresa, o Brasil aparece como o país mais frequente com 215 autores vinculados a instituições sediadas nesse país (70\%); seguido da Argentina, com 39 autores (13\%); e Portugal, com 14 autores (4\%). Outros países como Chile, Estados Unidos, Finlândia, Holanda, Inglaterra, Japão, Rússia, Suécia, Uruguai e Venezuela não aparecem no mapa por terem menos de quatro autores. Ainda que bastante pulverizado, $30 \%$ de todos os artigos publicados ao longo dos dez anos na História da Historiografia são oriundos de autores vinculados a instituições estrangeiras. Há, portanto, significativa participação internacional na revista, em consonância com o esforço de internacionalização do periódico que busca firmar-se como referência no espaço de língua portuguesa e espanhola. 


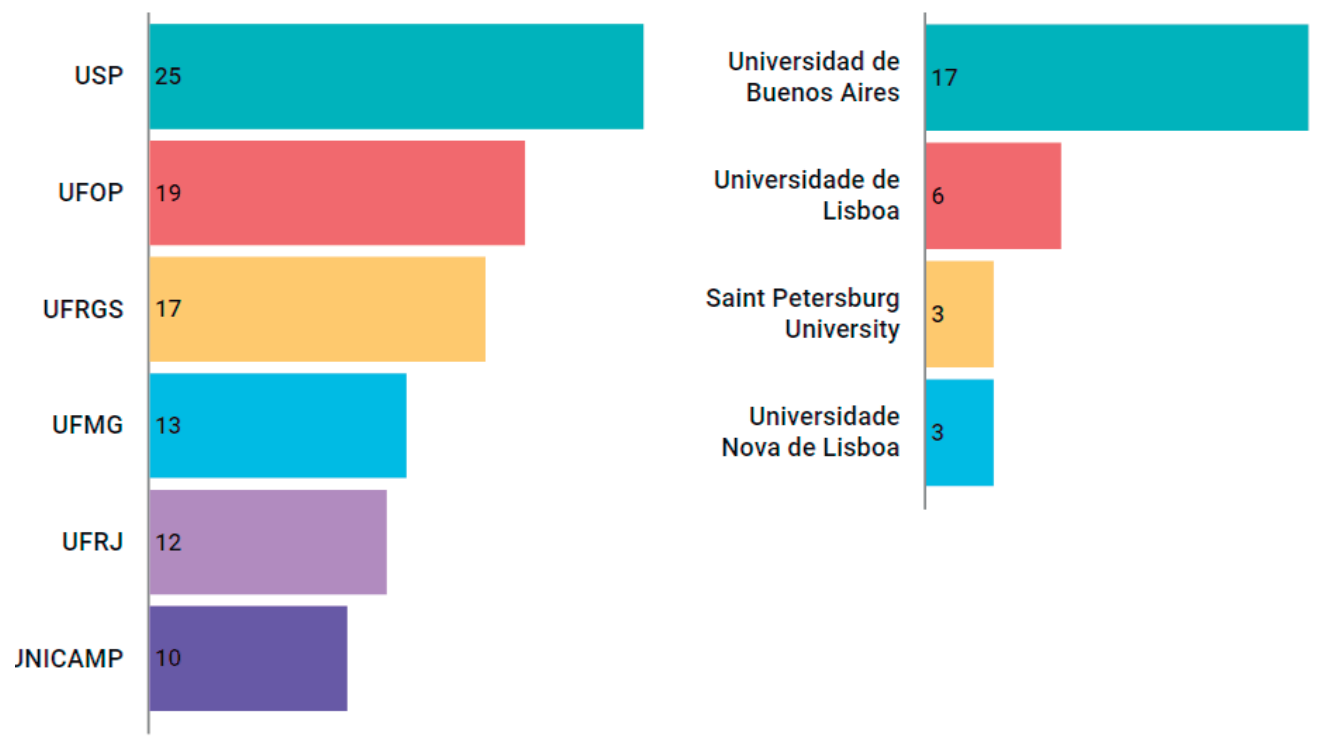

Gráfico 11 - Instituições mais frequentes brasileiras e internacionais

Dentre as 53 instituições brasileiras as quais os autores de artigos disseram-se vinculados, as três mais frequentes foram a Universidade de São Paulo, com 25 autores vinculados (8\%); a Universidade Federal de Ouro Preto, com 19 autores vinculados (6\%); e a Universidade Federal do Rio Grande do Sul, com 17 autores vinculados (5\%). Por meio da sistematização do número das instituições brasileiras, podemos atestar a grande diversidade institucional dos artigos publicados, boa prática editorial esperada de um periódico em alto estrato. Dentre as 60 instituições estrangeiras, considerou-se como as principais aquelas que tiveram três ou mais autores vinculados, despontando a Universidad de Buenos Aires, com 17 menções de filiação autoral (5\%); seguida pela Universidade de Lisboa, com 6 menções (2\%). A presença dessas instituições reflete a ênfase de pesquisadores sediados na Argentina e em Portugal como autores, já identificada no Gráfico 10. 


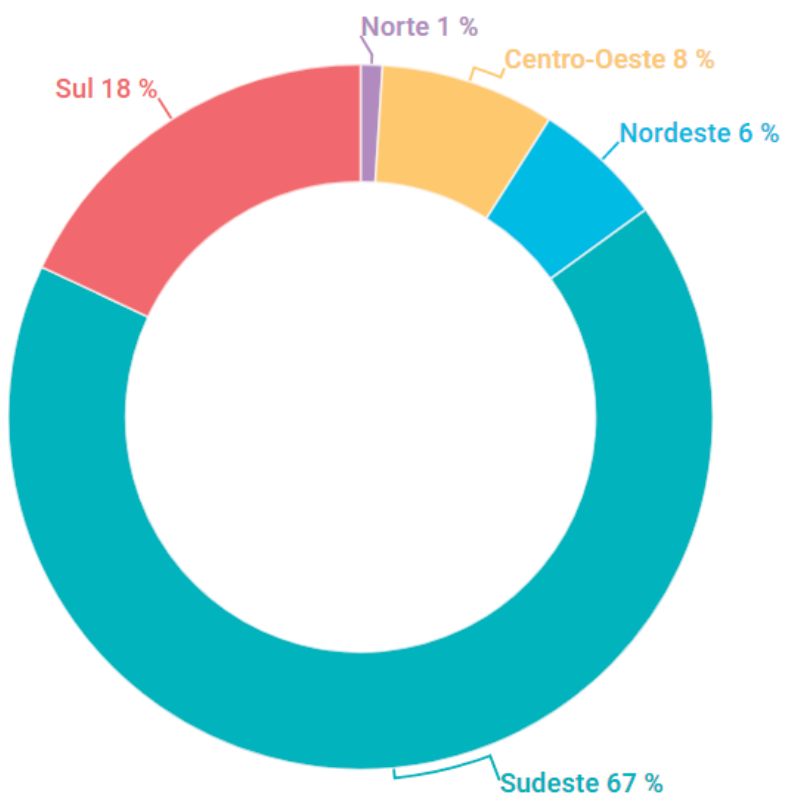

Norte

Centro-Oeste

Nordeste

Sudeste

Sul

Fazendo um recorte geográfico das instituições brasileiras às quais os autores de artigos estavam vinculados no momento da publicação, observou-se concentração nas sediadas no sudeste. De acordo com o Gráfico 12, 145 autores disseram estar vinculados a instituições dessa região (67\%); 38, a instituições do sul (18\%), 18, a instituições do centro-oeste $(8 \%) ; 13$, a instituições do nordeste $(6 \%)$ e 2 autores a instituições do norte (1\%).

Não obstante a concentração regional no sudeste, que deve ser ponderada levando em conta a dinâmica da ciência brasileira, pesquisas realizadas em todas as regiões geográficas do Brasil estão presentes na História da Historiografia. Utilizando - GEOCAPES, sistema de informações georreferenciadas da CAPES, para o ano de 2017, na área de História, observa-se que de um total de 2.084 docentes, 966 deles estão situados no sudeste $(46 \%) ; 457$ deles no sul $(22 \%) ; 178$ deles no centro-oeste $(9 \%) ; 403$ deles no nordeste $(19 \%)$; e 80 deles no norte $(4 \%)$. Entre os discentes da pós-graduação stricto 
sensu matriculados, de um total de 5298 alunos, 2856 deles estão situados no sudeste $(54 \%) ; 1145$ deles no sul $(21 \%)$; 429 deles no centro-oeste ( $8 \%) ; 727$ deles no nordeste (14\%); e 141 deles no norte (3\%). Realizando-se a comparação com os dois setores de autores com maior impacto na revista, professores do ensino superior e pós-graduandos, observase uma diferença mais acentuada entre as taxas de filiação de instituições do sudeste - 67\% autores da revista; $46 \%$ professores GEOCAPES; e 54\% pós-graduandos GEOCAPES - e do nordeste - 6\% autores da revista; $19 \%$ professores GEOCAPES; e $14 \%$ pós-graduandos GEOCAPES. De um ponto de vista numérico, o contingente de professores e pós-graduandos autores parece estar hiper-representado no sudeste e subrepresentado no nordeste.

\section{Perfil dos artigos}

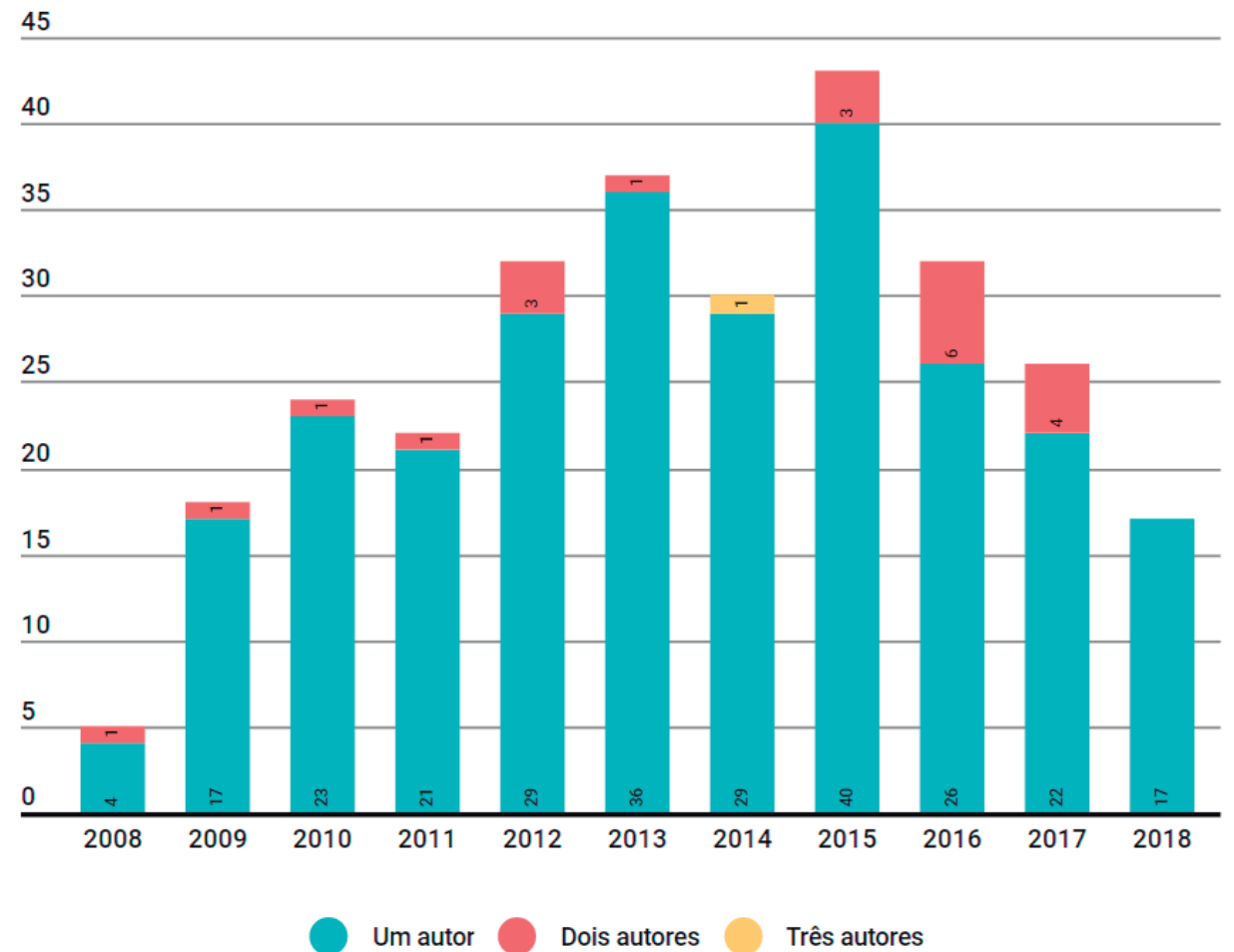

Gráfico 13 - Composição das autorias

Analisando-se todas as edições da revista, chegou-se à 
conclusão de que 263 artigos publicados (92\%) são de autoria única, sendo que 22 publicações ( $8 \%$ ) foram desenvolvidas por grupos de 2 a 3 autores. O periódico parece refletir a política da área de História que tradicionalmente privilegia publicações de autoria única. Em relação à autoria dos artigos, observouse, ainda, que 237 autores (87\%) publicaram 1 artigo nas edições analisadas e 32 autores (12\%) publicaram 2 artigos ao longo dos dez anos de existência da revista, número pouco expressivo. Destacam-se como os autores mais prolíficos da revista Francisco Murari Pires, com 4 artigos, e Nicolás Lavagnino, com 3 artigos.

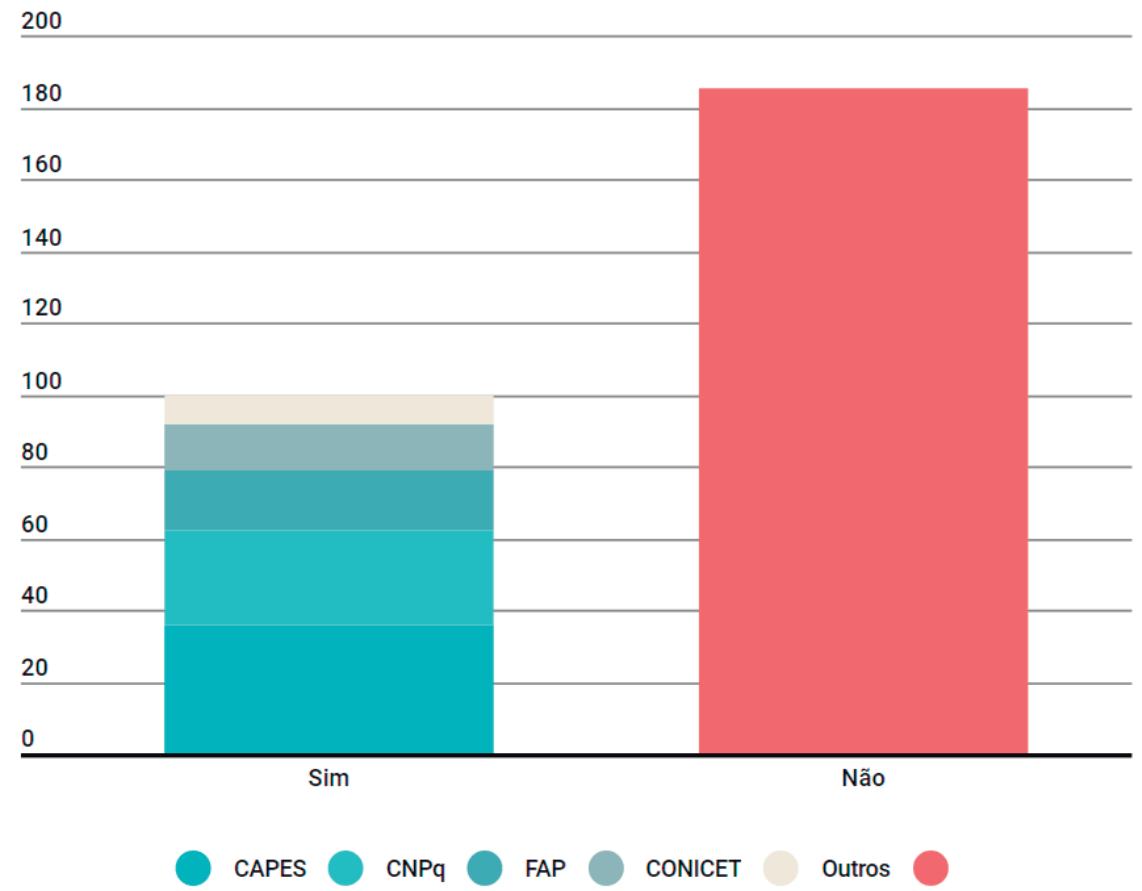

Gráfico 14 - Financiamento e fonte

No que diz respeito ao financiamento das pesquisas publicadas na História da Historiografia, observou-se que, dos 285 artigos publicados, 185 deles (65\%) são resultado de pesquisa desenvolvida sem financiamento; e 100 deles (35\%) com financiamento. Dentre as agências de financiamento, as mais frequentes foram a CAPES, financiando 36 artigos (36\%); o CNPq, financiando 26 artigos (26\%); fundações de amparo à pesquisa regionais, financiando 17 artigos (17\%); e o Consejo 
Nacional de Investigaciones Científicas y Técnicas (CONICET), financiando 13 artigos (13\%). As fundações regionais citadas foram a Fundação de Apoio a Pesquisa do Distrito Federal (FAPDF), FAPEMIG, FAPERJ e Fundação de Amparo à Pesquisa do Estado de São Paulo (FAPESP). Não houve nem um artigo publicado com financiamento privado.

Desde o número 5, de 2010, consta nas normas de publicação do periódico que os autores, ao submeterem seus textos para análise, devem indicar a instituição financiadora da pesquisa. Nesse sentido, ou os autores vêm sistematicamente deixando de atribuir à agência financiadora os créditos em suas pesquisas ou a maioria das pesquisas publicadas na revista não obteve nem um tipo de financiamento. De qualquer forma, o baixo índice de autores pós-graduandos ou pós-graduados $(28 \%)$, visto no Gráfico 7 , também pode ter contribuído para o baixo número de artigos com financiamento.

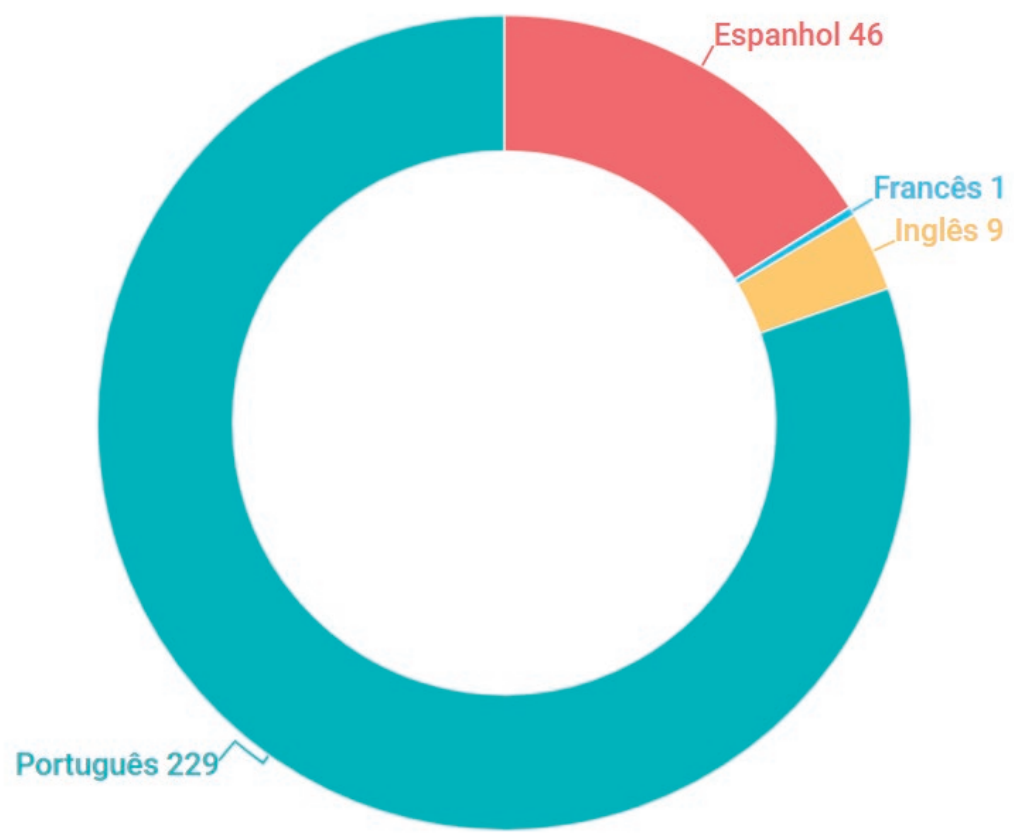

Gráfico 15 - Idioma de publicação

Devido à expressiva presença de autores vinculados a instituições brasileiras (70\%), mostrada no Gráfico 10, não surpreende que o idioma mais frequente dos artigos publicados 
na História da Historiografia seja a língua portuguesa, com 229 artigos (80\%). O número é ligeiramente maior do que o do vínculo institucional, pois alguns artigos são de pesquisadores portugueses e outros são traduções de artigos para o português de pesquisadores sediados em universidades estrangeiras. $O$ segundo idioma mais frequente é o espanhol, com 46 artigos (16\%), em conformidade com a política editorial da revista de situar-se como um fórum de debate nas comunidades lusófona e hispanófona.

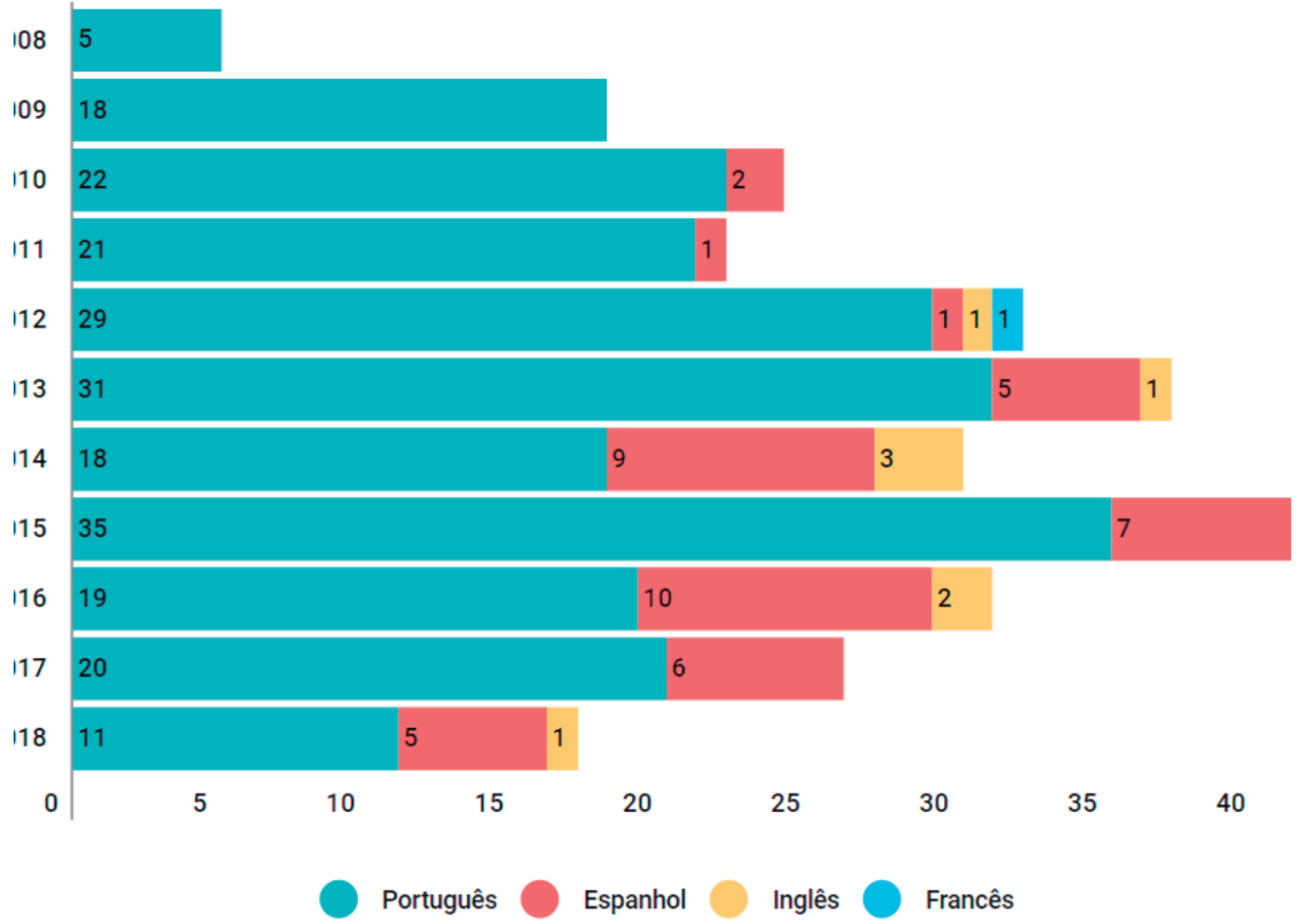

Gráfico 16 - Idioma de publicação por ano

Acompanhando a evolução do idioma dos artigos publicados na História da Historiografia ao longo desses dez anos de existência, percebe-se que, a partir de 2013, o número de artigos publicados em língua estrangeira começa a ser expressivo. Em 2010, são publicados 2 artigos em língua estrangeira (8\%); em 2011, 1 artigo (4\%); em 2012, 3 artigos (9\%); em 2013, 6 artigos (16\%); em 2014, 12 artigos (40\%); em 2015, 8 artigos (18\%); em 2016, 12 artigos (39\%); em 2017, 6 artigos (23\%); e, em 2018, 7 artigos (36\%). Em 2008 e 2009, não houve publicação 
em língua estrangeira. É importante notar que, desde 2013, a revista passou a contar com um pesquisador argentino em seu Conselho Executivo, o que deve ter contribuído para o aumento do interesse de pesquisadores falantes do espanhol no periódico, segunda língua mais frequente utilizada nos artigos (16\%).

\section{Conteúdo dos artigos}

Desde a sua fundação, a História da Historiografia disponibilizou aos autores um banco de palavras-chave, que ajudou a normatizar e guiar o uso dos termos que servem para indexação de cada contribuição publicada. Os autores foram, portanto, estimulados a utilizar as palavras-chave sugeridas pelos editores, não obstante ser possível pedir a inclusão de alguma que julgassem pertinentes. Tendo isso em vista, as palavras-chave pareceram um índice confiável nesse primeiro esforço de mapear o conteúdo publicado ao longo dos dez anos do periódico. Analisando os artigos, a grande maioria apresenta um total de três palavras-chave, sendo que dois artigos possuem quatro palavras-chave.

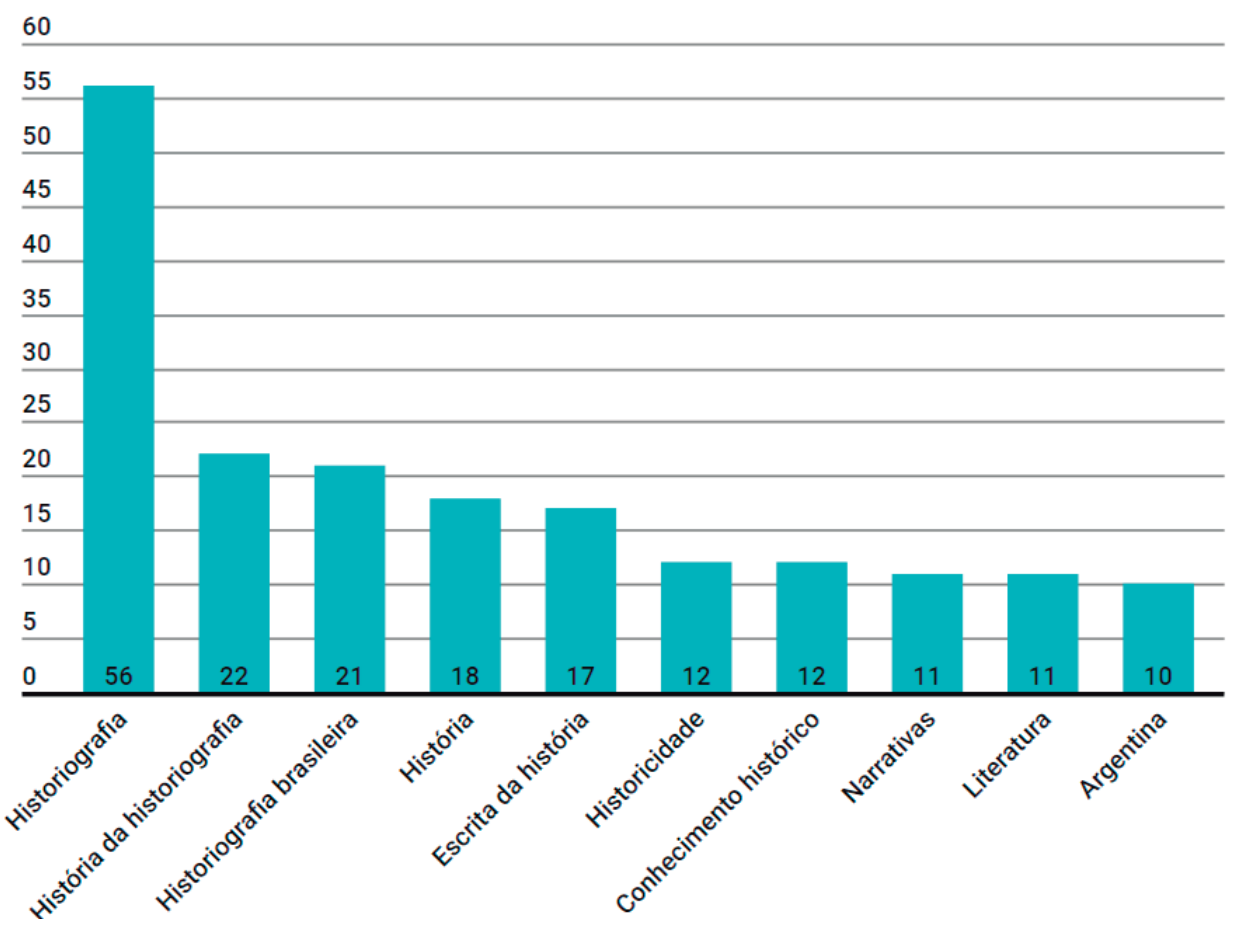


No conjunto das 355 palavras-chave únicas utilizadas pelos autores como representativas de seus artigos, verificouse que historiografia foi a mais frequente dentre as palavraschave, reivindicada 56 vezes e usada em $20 \%$ dos artigos, seguida de história da historiografia, com 22 utilizações e usada em $8 \%$ dos artigos.

O alto índice de entradas para historiografia talvez seja explicado pela polissemia da palavra que, muitas vezes, abarca o entendimento mais recente para história da historiografia. O uso de historiografia para designar algo muito parecido ou idêntico à história da historiografia já pode ser notado em obras como a de José Honório Rodrigues, em que situava historiografia como a história da história. No mesmo período, Francisco Iglésias separava a historiografia, como uma obra de História, da história da historiografia, o estudo da história desses livros (TORRES 2007). ${ }^{5}$ Portanto, desde os estudos seminais e iniciais sobre a história da escrita da história no Brasil, tanto historiografia quanto história da historiografia foram usadas para se referir à «história das formas de produção da verdade histórica» (ARAUJO 2006, p. 91). Possível índice da mescla dessas duas palavras-chave é o fato de que nem um autor que escolheu usar a palavra historiografia utilizou também história da historiografia como palavra-chave. Por outro lado, parece claro que, muitas vezes, a palavra-chave historiografia é usada para definir o objeto de investigação do artigo. Diversos autores que optaram por essa palavra-chave realizaram uma investigação da produção histórica em épocas as mais variadas através da historiografia.

Entre os artigos publicados nas edições da História da Historiografia, 78 deles (27\%) possuem como palavra-chave historiografia ou história da historiografia.
5 - Para o uso difundido da palavra historiografia a partir da década de 1930 e 1950 para designar aquilo que os historiadores fazem, vide: NICODEMO; SANTOS; PEREIRA 2015. 


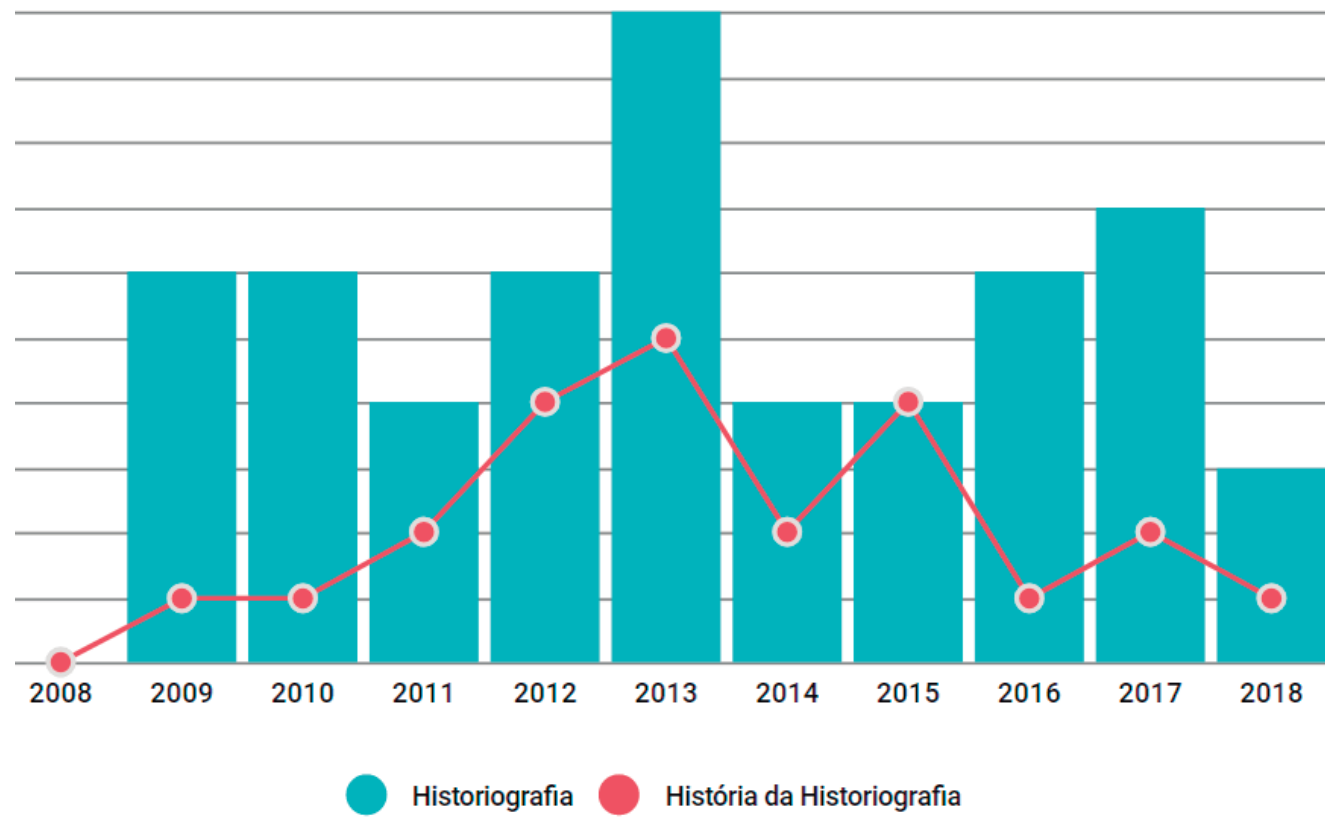

Gráfico 18 - Frequência das palavras-chave historiografia e história da historiografia

Comparando o ano com a quantidade de utilizações das palavras-chave historiografia e história da historiografia, percebe-se que há um leve crescimento na utilização de história da historiografia entre os anos 2011 e 2013. Porém, como são períodos muito específicos, pode-se dizer que ao longo desses dez anos a palavra história da historiografia não substituiu historiografia nos artigos publicados, mesmo com a maior visibilidade e definição teórica fomentada pela escolha do nome do periódico.

Ainda no universo das palavras-chave, verificou-se que houve a preferência de alguns autores por especificar o tipo de historiografia sobre a qual seus trabalhos se debruçavam. 


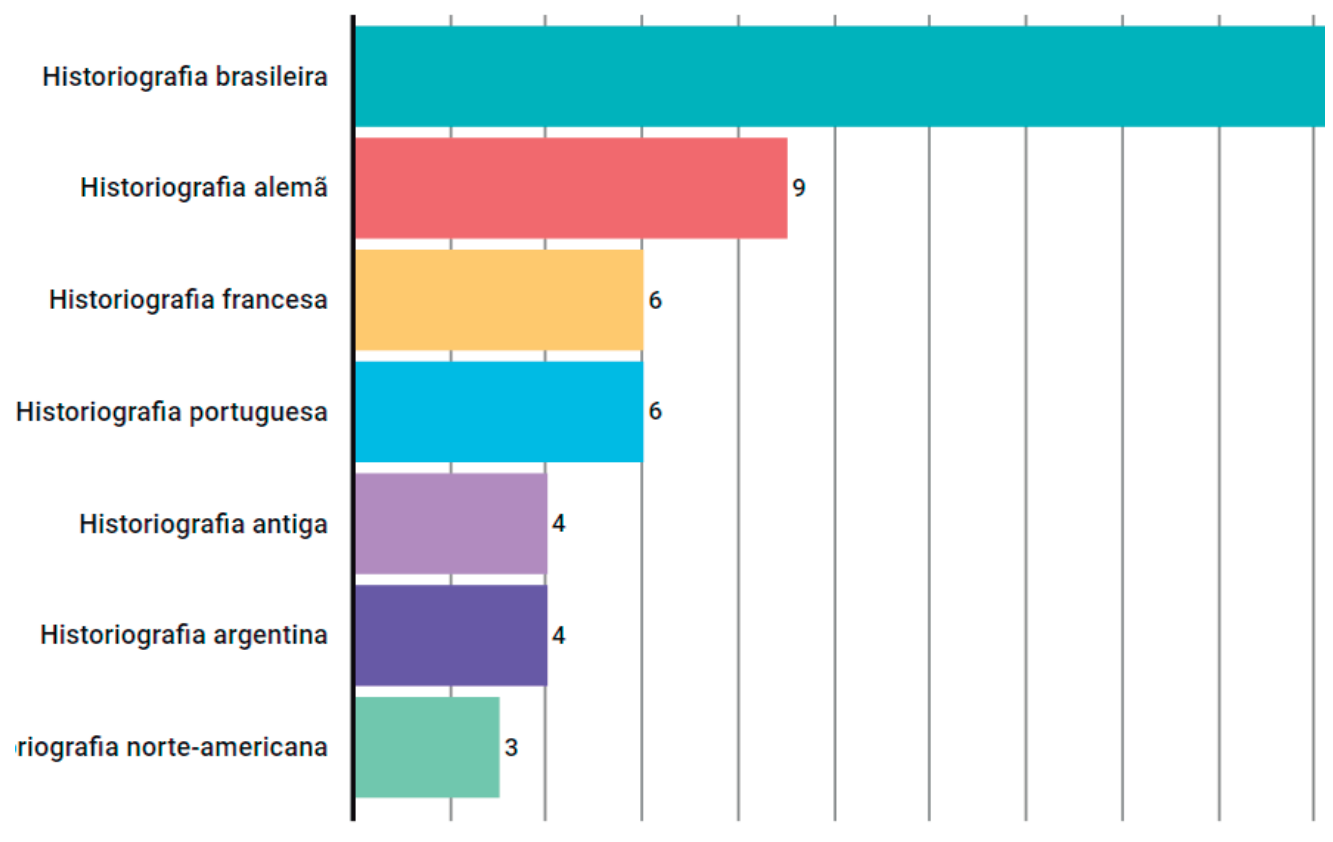

Gráfico 19 - Palavras-chave com historiografia

As palavras-chave mais frequentes que continham historiografia foram historiografia brasileira; historiografia alemã; historiografia francesa; historiografia portuguesa; historiografia antiga; historiografia argentina e historiografia norte-americana. Foram descartadas para a confecção desses dados as palavras-chave historiografia do século XIX e historiografia do século XX, cada uma com quatro utilizações, por abarcarem séculos, não configurando um recorte temático. A palavra-chave história da historiografia brasileira foi escolhida por apenas um autor e não existe nem uma outra entrada para história da historiografia adjetivada. Em análises futuras, é preciso levar em conta as induções provocadas pelos dossiês publicados no periódico, tais como o "Historiografia alemã: abordagens e desenvolvimentos", uma vez que dos 4 artigos publicados 3 deles escolheram a palavra-chave historiografia alemã.

Abrindo um pouco mais o leque das palavras-chave presentes nos artigos, temos a representação gráfica, no Gráfico 20, dos dados bibliométricos colhidos. 


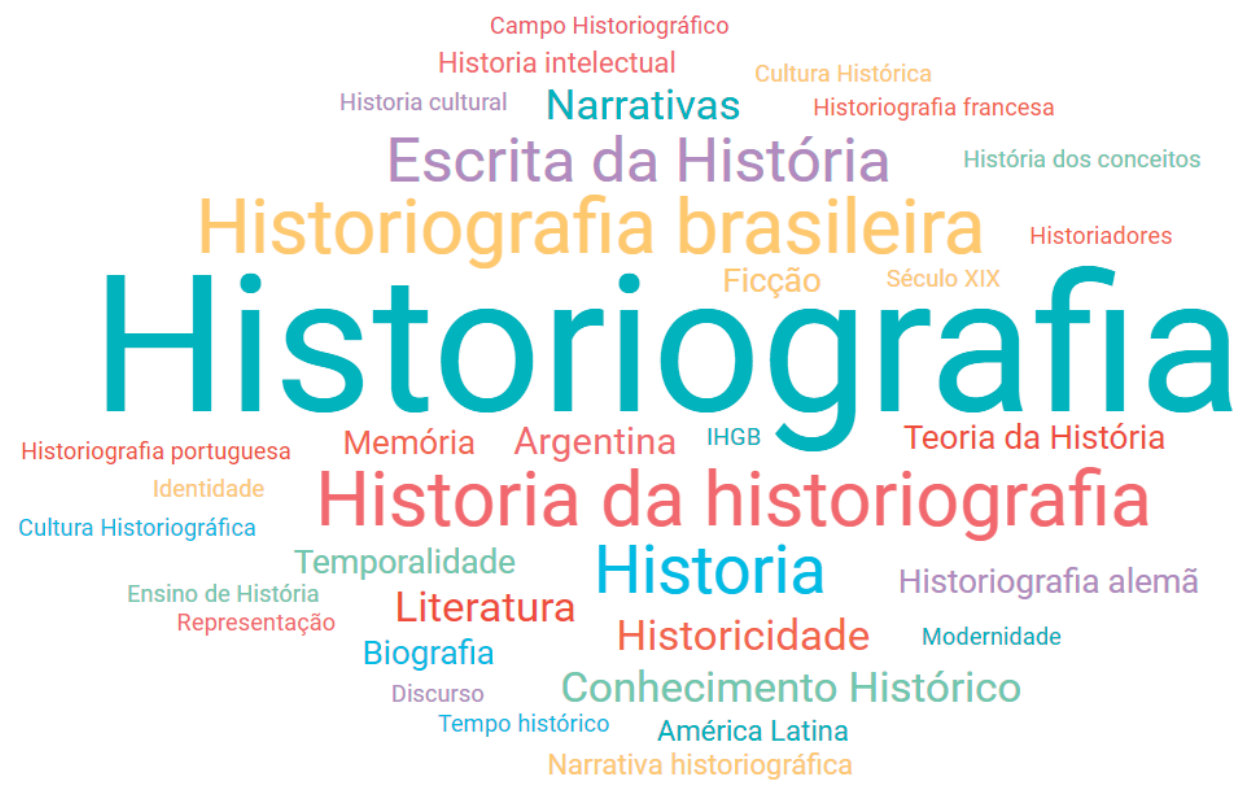

Gráfico 20 - Palavras-chave

Nela, além das dez palavras-chave mais frequentes anteriormente analisadas, podemos ver também outras com menor utilização. É nesse conjunto mais alargado que surpreendentemente encontramos teoria da história, área central de temática do periódico, mas pouco reivindicada pelos autores como palavra-chave, figurando em apenas 8 artigos (3\%) em um total de 285. Mostra-se, importante, apesar de espinhosa, a tarefa de distinguir não apenas quais artigos publicados podem ser categorizados dentro da teoria da história, mas também identificar quais poderiam ser concebidos como realizando uma história da historiografia. De imediato, a pluralidade semântica desses dois campos investigativos e a própria possiblidade de a história da historiografia ser um campo de investigação autônomo tornam uma definição do que seja a teoria da história e a história da historiografia necessária. Dessa forma, utilizou-se na categorização dos artigos o entendimento de teoria da história como sinônimo para epistemologia da história, como "um movimento de reflexão sobre o métier dos historiadores [ou seja], um campo metateórico" (MELLO 2012b, p. 377). Por outro lado, aqueles artigos que se propunham a efetuar um estudo crítico da escrita da história foram classificados como pertencentes 
à história da historiografia (ARAUJO 2013, p. 35). A história da escrita da história não deve ser confundida com a história da disciplina História, visto que a história da historiografia não busca investigar sob um ponto de vista evolutivo e teleológico o fazer histórico, mas desvelar a sua historicidade (ARAUJO 2006, p. 91). História da historiografia, portanto, não se confunde com um encômio da ciência histórica, com a historiografia ou com os famosos balanços historiográficos, que aparecem no conteúdo da revista e, por isso, tiveram uma entrada própria.

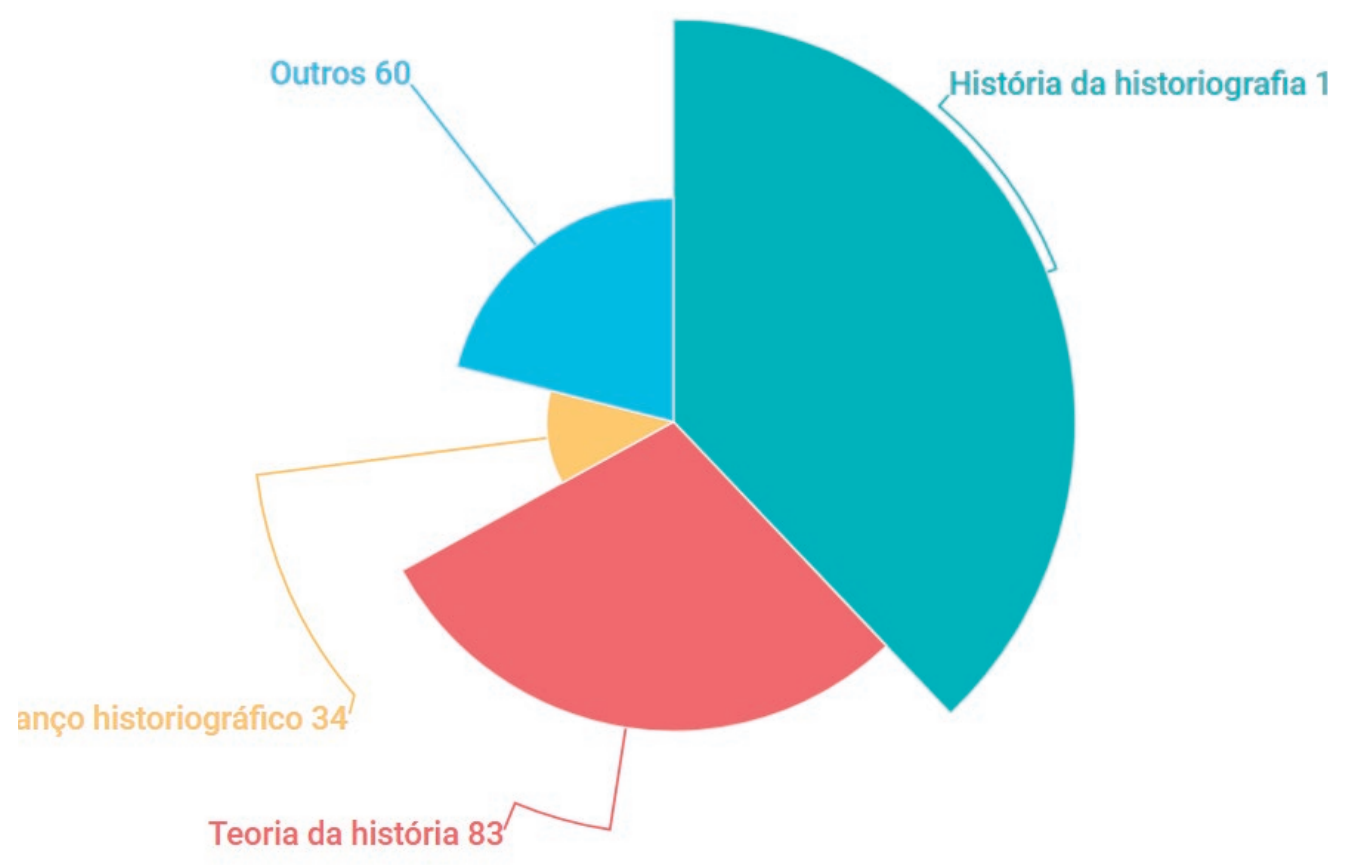

\section{Gráfico 21 - Áreas temáticas}

Categorizando, portanto, os artigos em teoria da história, história da historiografia e balanço historiográfico, obteve-se que, entre os 285 artigos publicados no periódico, 108 deles (38\%) são de história da historiografia, 83 deles (29\%) são de teoria da história e 34 deles (12\%) são de balanço historiográfico. A partir do Gráfico 21, percebe-se uma paridade maior entre as pesquisas em história da historiografia e teoria da história, ausente no Gráfico 20. Também é possível afirmar que essas duas áreas juntas englobam $67 \%$ de todos os artigos publicados. Concentração esperada e até mesmo desejada, já que a revista 
foi "criada com o propósito de reunir pesquisadores da área de teoria da história e história da historiografia" (CALDAS; MATA; ARAUJO 2011, p. 10).

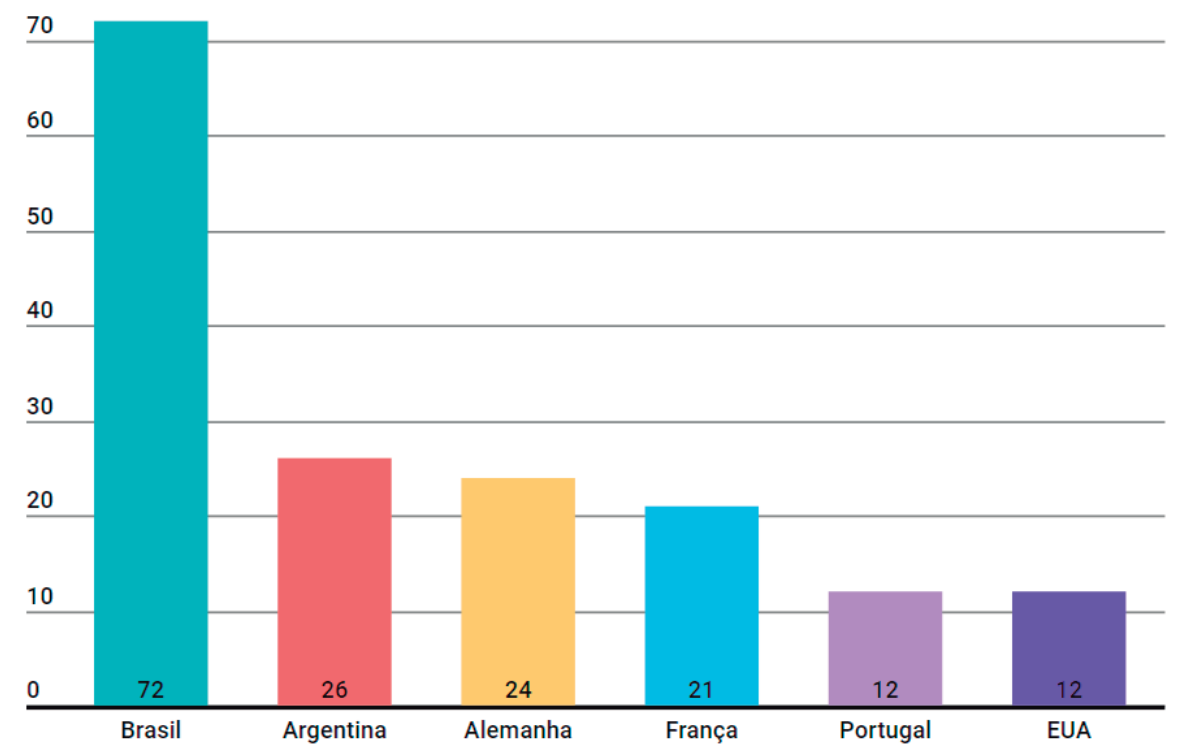

Gráfico 22 - Países mais estudados

Os países mais estudados pelos artigos publicados na História da Historiografia foram Brasil, com 72 artigos (25\%); Argentina, com 26 artigos (9\%); Alemanha, com 24 artigos (8\%); França, com 21 artigos (7\%); Portugal, com 12 artigos (4\%); e Estados Unidos, com 12 artigos (4\%). Esses dados dizem respeito aos artigos que tiveram exclusivamente esses países - muitas vezes via autores estudados - como objeto de análise. Alguns artigos abarcaram dois ou mais países (24\%), outros múltiplos países ou foi impossível identificar qualquer traço de nação (19\%). A centralidade nos estudos brasileiros, argentinos, alemães, franceses, portugueses e estadunidenses, já presente no Gráfico 19, é novamente vista no Gráfico 22, porém em ordem diferente. 


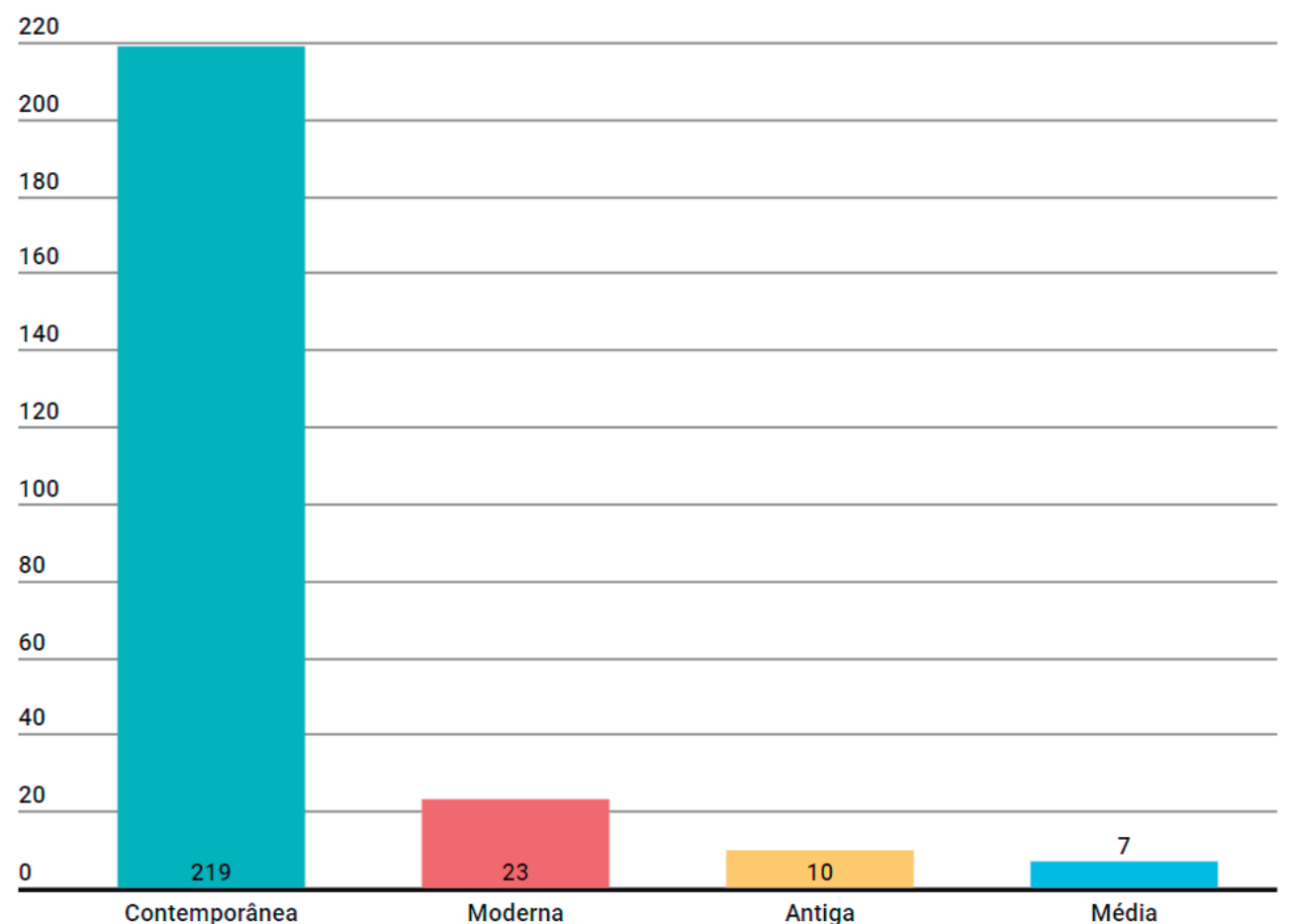

Gráfico 23 - Épocas mais abordadas

O período histórico mais estudado pelos artigos, acentuadamente, é o contemporâneo, com 219 artigos (77\%); seguido pelo moderno, com 23 artigos (8\%); antigo, com 10 artigos (4\%); e médio, com 7 artigos (2\%). Não foi possível classificar temporalmente 22 artigos (8\%) e outros 4 artigos $(1 \%)$ os quais abordavam tanto a idade moderna quanto a contemporânea. Observa-se, portanto, que a maioria dos artigos publicados na História da Historiografia versa sobre autores ou problemas situados na contemporaneidade.

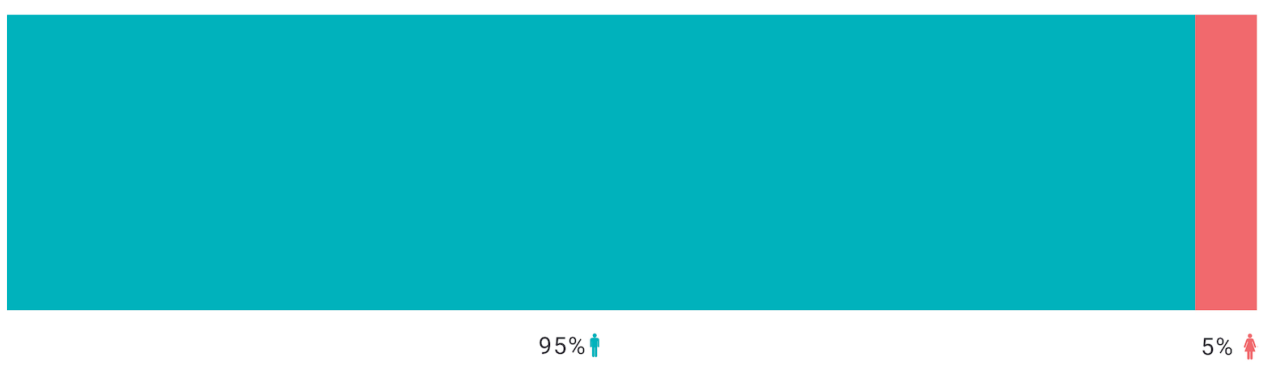

Gráfico 24 - Percentual de autores estudados segundo o sexo 
Os autores estudados nos artigos, que aparecem no título ou resumo, somaram 195, sendo 186 deles do sexo masculino (95\%) e 9 deles do sexo feminino (5\%). Nota-se que não obstante a importância, desde a década de 1980, dos estudos de gênero na reavaliação das práticas históricas e historiográficas, não houve impacto significativo dessas questões nas pesquisas publicadas na revista. As únicas nove mulheres que tiveram suas obras analisadas foram: Alice Piffer Canabrava, Cecília Westphalen, Dorothea Lange, Hannah Arendt, Laura de Mello e Souza, Maria de Fátima Bonifácio, Maria Yedda Linhares, Teresa Piossek Prebisch e Wlamyra R. Albuquerque. Tendo em vista a centralidade da idade contemporânea demonstrada no Gráfico 23, não é de se estranhar que todas as autoras analisadas em artigos situemse nessa faixa cronológica, em especial nos séculos XX e XXI. A exceção de Arendt, que figurou em dois artigos, as demais autoras foram alvo de investigação em um artigo.

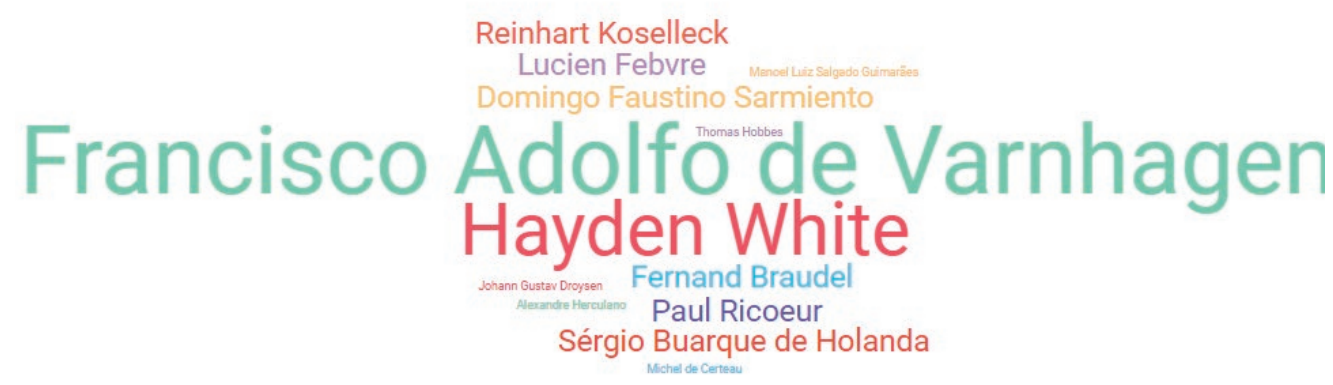

Gráfico 25 - Autores mais estudados

Dente os 186 autores estudados, destacam-se entre eles: Francisco Adolfo de Varnhagen, com 7 artigos; e Hayden White, com 6 artigos. Foram alvo de investigação em quatro artigos: Domingo Faustino Sarmiento; Fernand Braudel; Lucien Febvre; Paul Ricoeur; Reinhart Koselleck; e Sérgio Buarque de Holanda. Foram alvo de investigação em três artigos: Alexandre Herculano; Johann Gustav Droysen; Manoel Luiz Salgado Guimarães; Michel de Certeau; Thomas Hobbes e Tucídides. Nem uma mulher encontra-se entre os autores que obtiveram três ou mais estudos, não estando no mapa dos autores mais estudados. Dentre os autores mais pesquisados, há preferência por autores franceses (4), seguidos por brasileiros (3). 


\section{Outras seçōes e os novos rumos do periódico}

A natureza das contribuições presentes na História da Historiografia foi sendo delimitada com o passar do tempo. Em sua fundação, a revista publicava artigos inéditos, resenhas críticas de livros e traduções de textos. Como se pode ver na tabela 1, além das seções artigo e resenha, foram incluídas as seções texto e documento historiográfico (TDH) - textos clássicos traduzidos ou transcritos e comentados - e, logo em seguida, a entrevista, em 2009.

\begin{tabular}{|c|c|c|c|c|}
\hline Edição & Artigo & Resenha & TDH & Entrevista \\
\hline n. 1 & 5 & 2 & 0 & 0 \\
\hline n. 2 & 10 & 4 & 1 & 0 \\
\hline n. 3 & 8 & 8 & 1 & 1 \\
\hline n. 4 & 12 & 10 & 1 & 1 \\
\hline n. 5 & 12 & 7 & 1 & 1 \\
\hline n. 6 & 9 & 9 & 1 & 0 \\
\hline n. 7 & 13 & 10 & 0 & 2 \\
\hline n. 8 & 8 & 9 & 0 & 1 \\
\hline n. 9 & 11 & 9 & 0 & 1 \\
\hline n. 10 & 13 & 6 & 1 & 1 \\
\hline n. 11 & 13 & 7 & 1 & 1 \\
\hline n. 12 & 11 & 7 & 1 & 1 \\
\hline n. 13 & 13 & 8 & 0 & 0 \\
\hline n. 14 & 7 & 8 & 1 & 0 \\
\hline n. 15 & 9 & 6 & 0 & 0 \\
\hline n. 16 & 14 & 7 & 0 & 0 \\
\hline n. 17 & 19 & 2 & 1 & 1 \\
\hline n. 18 & 15 & 5 & 1 & 1 \\
\hline n. 19 & 9 & 4 & 0 & 1 \\
\hline n. 20 & 9 & 2 & 0 & 1 \\
\hline n. 21 & 7 & 3 & 0 & 0 \\
\hline n.22 & 15 & 3 & 0 & 1 \\
\hline n. 23 & 7 & 1 & 1 & 0 \\
\hline & & & & \\
\hline
\end{tabular}




\begin{tabular}{|c|c|c|c|c|}
\hline n. 24 & 10 & 1 & 0 & 0 \\
\hline n. 25 & 9 & 1 & 1 & 1 \\
\hline n. 26 & 9 & 3 & 0 & 0 \\
\hline n. 27 & 8 & 0 & 0 & 0 \\
\hline
\end{tabular}

Quadro 1 - Número de artigos, resenhas, TDH e entrevistas publicados

Além dessas seções, em 2016, foi inaugurada a em pauta com a conferência de abertura de Rodrigo Patto Sá Motta, à época presidente da Associação Nacional de História (ANPUH), no XXVIII Simpósio Nacional de História, ocorrido em 2015 em Florianópolis. Além desse texto, a seção só abrigou mais um, na edição seguinte, e, por isso, essa característica não consta no levantamento efetuado. Outra peculiaridade importante aconteceu no número 26 , em que uma tradução de artigo recente foi publicada na seção texto e documento historiográfico, prática incomum. Porém, como não consta a edição completa, não foi possível conferir a informação. De qualquer forma, os números levantados permitem-nos afirmar que, desde a fundação da História da Historiografia, houve uma preocupação evidente em valorizar a seção resenha expressa nos números abaixo do Gráfico 26.

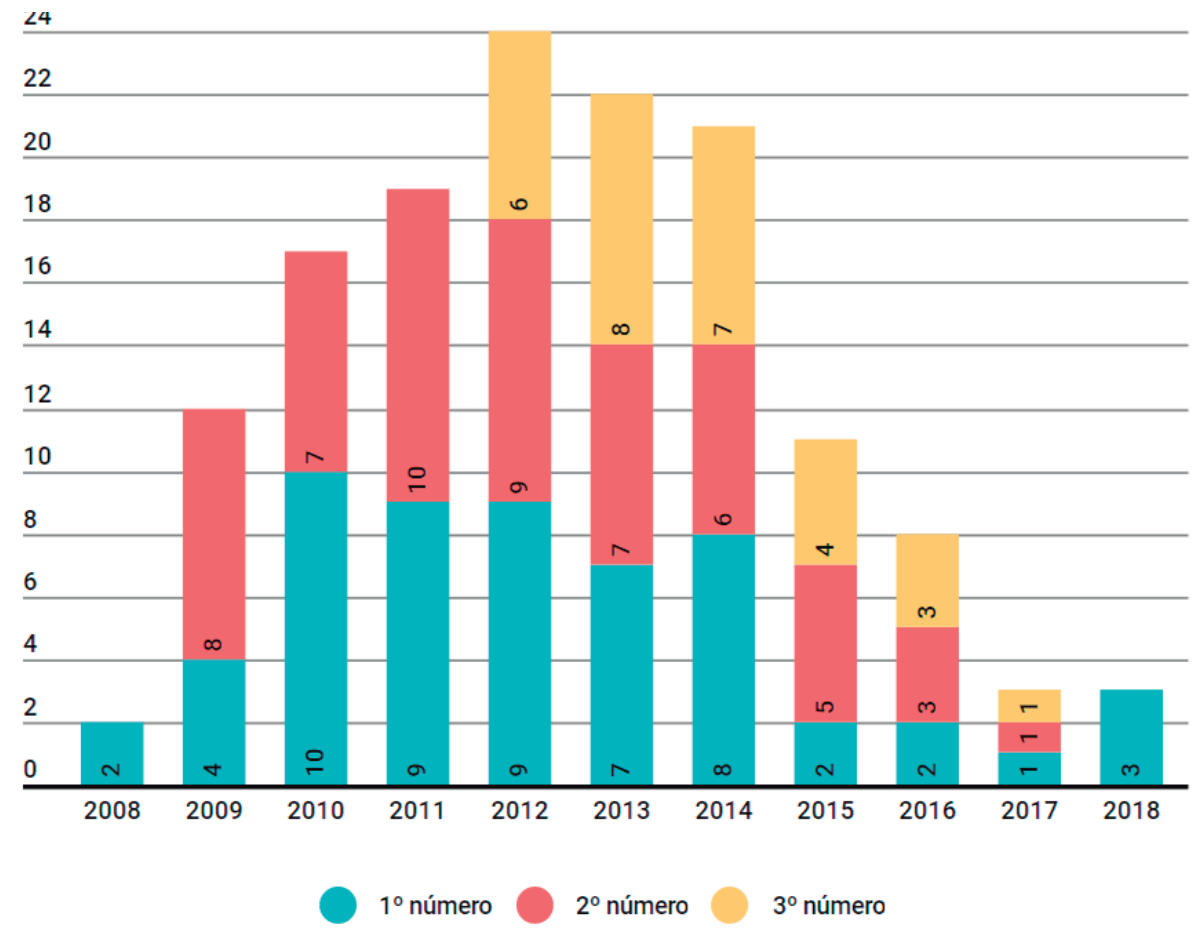


Em 2010, os editores da revista reforçavam a importância das resenhas como "um veículo de discussão e reflexão cada vez mais requisitado", que ajudava na promoção de "um debate efetivo no campo" (OS EDITORES 2010a, p. 8). Esse esforço de manter os leitores atualizados sobre as principais obras publicadas no campo da história da historiografia e da teoria da história, sem esquecer a manutenção do debate qualificado em relação a essas obras, contribuiu para que o número de resenhas publicado crescesse com a consolidação da revista. Em 2013 e 2014, observamos uma leve queda na quantidade de resenhas publicadas, que se aprofundou nas edições dos anos seguintes, chegando ao ponto do último número lançado não conter nem uma resenha publicada. A redução no número de resenhas a partir de 2015 pode ser atribuída à mudança na política editorial, que deixou de estimular o envio de contribuições para essa seção.

É uma constante preocupação no horizonte editorial a qualidade dos textos publicados, e, muitas vezes, as resenhas são acusadas de serem textos exclusivamente informativos, ou muito elogiosos ou simplesmente mal escritos. No esforço de dar maior qualidade para a seção, os editores reformularam, em 2011, as suas diretrizes, explicitando três tipos de resenha que a revista receberia: crítica, resumo e temática.

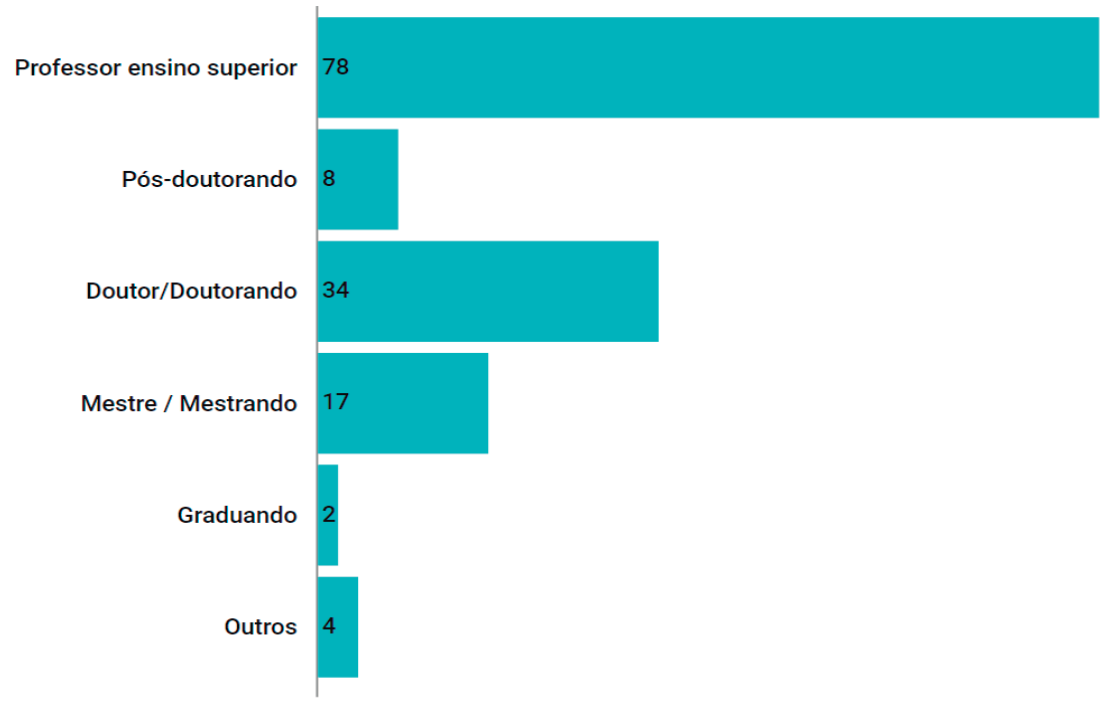


A partir do levantamento da situação acadêmica dos 143 autores de resenha, descobriu-se que 78 deles (54\%) são professores do ensino superior; 34 deles (24\%) são doutores ou doutorandos; 17 deles (12\%) são mestres ou mestrandos; 8 deles são pós-doutorandos (6\%); e 2 deles (1\%) são graduandos. Professores do ensino técnico-tecnológico e pesquisadores somaram 4 autores (3\%). É tarefa bastante difícil a de interpretar dados quantitativos tomando-os como qualitativos, sendo importante frisar, contudo, que os dados sobre a situação acadêmica dos autores de resenha mostramse muito próximos daqueles dos autores de artigos, conforme Gráfico 7. As duas seções, inclusive, apresentam autores em todas as faixas, com contribuições de graduandos até professores titulares, refletindo o desejo dos editores da revista de não préselecionar as contribuições recebidas segundo a titulação.

As resenhas não foram apenas essenciais na "política de redação dos principais periódicos de ciências humanas surgidos entre fins do século XIX e começo do século $X X^{\prime \prime}$, mas se constituíram como espaços "decisivos para fomentar o debate intelectual e contribuir para a organização do campo disciplinar" (ROCHA 2018, p. 20, p. 44). A resenha não é uma prática iniciada com os periódicos especializados ligados a instituições de ensino superior. Como gênero textual, compôs muitas das revistas que existiram antes do processo de disciplinarização da História. Seu remodelamento, para estar em sintonia com a prática científica, envolveu a padronização de alguns elementos, como o conhecimento especializado do resenhista no tema, composição de um texto analítico centrado em apenas uma obra, a avaliação crítica da obra para o campo, entre outros aspectos (ROCHA 2018, p. 20,43-44).

As resenhas, em diversos contextos de publicação, foram espaços críticos cativos importantes que contribuíram para pautar as discussões historiográficas, que certamente não se resumem aos artigos. Importantes periódicos como o Jahrbuch für Romanische und Englische Literatur e a Revue Critique d'Histoire et de Littérature dedicavam-se a publicação exclusiva 
de resenhas em seus números (ROCHA 2018, p. 20, 42). Ao longo dos dez anos de existência da História da Historiografia, a seção resenha passou de lugar de centralidade para o de inexistência. Desde o número 27, de 2018, a revista não conta mais com nem um outro tipo de material que não seja artigo. Apesar da tradição de publicação de resenhas dentro das humanidades, da importância reconhecida das resenhas como espaços de debate rápido em relação à produção recente e, talvez mais importante, da recomendação de publicação de resenhas críticas, dentre os critérios qualitativos, pela documentação da área de História sobre o Qualis Periódico (FICO; WASSERMAN; MAGALHÃES 2016) essa seção como as de texto e documento historiográfico, entrevista e em pauta, consideradas por seus editores como uma espécie de memória do campo da história da historiografia e da teoria da história no Brasil, foram transferidas para o portal HHMagazine: humanidades em rede (https://hhmagazine.com.br), lançado recentemente. Voltado para a divulgação científica e o debate público sobre as humanidades em diversos suportes, como podcast e vídeo, o portal permitirá maior flexibilidade na forma das contribuições. Aliado a isso, a migração dessas seções para o HHMagazine: humanidades em rede também tem como objetivo desafogar a vultuosa demanda comum em uma revista de alto estrato, contribuindo para que haja maior direcionamento das atividades e, não menos importante, dos recursos na contribuição de maior valor científico na atualidade: o artigo. Com essa mudança na política editorial da História da Historiografia, passou-se também a receber, além dos tradicionais artigos originais e inéditos, artigos de debate historiográfico, com tamanho e formato igual ao artigo inédito e original, mas que buscam resenhar criticamente publicações nas áreas temáticas e correlatas do periódico.

Em 2018, em consonância com a proposta de internacionalização da História da Historiografia, o subtítulo International Journal of Theory and History of Historiography também foi incorporado. Outro elemento importante nessa nova fase da revista é a atualização de seu projeto gráfico 
ocorrido no número 26, de 2018, e realizado por Marianna Andrade Melo. Essa mudança, segundo os editores, objetiva não "[...] somente modernizar o aspecto visual da História da Historiografia, mas também tornar a leitura dos artigos mais prazerosa e eficaz para nossos leitores e leitoras" (OS EDITORES 2018, p. 11).

\section{Consideraçōes finais}

Acompanhando o crescimento das universidades, a especialização e o desenvolvimento da disciplina História, muitos periódicos foram fundados desde meados do século XIX, passando por diversas demandas e respostas aos múltiplos contextos que estavam inseridos (ROCHA 2018, p. 39). O atual momento de busca pela internacionalização dos periódicos brasileiros e internacionais deixa entrever as dificuldades de se manterem diretrizes e agendas próprias de pesquisa e, ao mesmo tempo, adequar-se a normas que são supranacionais. A proposta de mensurar a produção científica brasileira para avaliar e sugerir boas práticas editoriais vem sendo adotada desde a década de 1990 pelas agências de fomento, acarretando na adoção de parâmetros avaliativos - bases de dados geridas por organismos internacionais (SILVEIRA; BENEDET; SANTILLÁN-ALDANA 2018, p. 93-95), ficando de fora inclusive a avaliação do periódico no Qualis como forma de aferir sua internacionalização (BARATA 2016 apud SILVEIRA; BENEDET; SANTILLÁN-ALDANA 2018, p. 98). Não é demasiado lembrar que a busca pela internacionalização trouxe o paradoxo de julgar a produção acadêmica brasileira por parâmetros transnacionais e, muitas vezes, chegar à conclusão de sua invisibilidade baseada na ausência de indexadores controlados por grandes grupos comerciais (SILVEIRA; BENEDET; SANTILLÁN-ALDANA 2018, p. 94). A pressão, portanto, que os editores da História da Historiografia têm vivido pela internacionalização do periódico é elemento central nas diversas reformulações que a revista 
passou, não sendo exagero dizer que esteve mesmo presente no horizonte de sua fundação. O novo formato adotado pela revista de publicar exclusivamente artigos parecer ser uma resposta a essas demandas, assim como a mudança na periodicidade e a incorporação de pesquisadores internacionais em seu Conselho Executivo.

Por fim, fica também o questionamento sobre o impacto dos artigos no debate acadêmico dentro da área. Apesar de bastante preliminares, pesquisas indicam que a centralidade atribuída à publicação em periódico pelo sistema de avaliação da CAPES não é a mesma atribuída pelos pesquisadores. Os artigos, mesmo aqueles publicados em revistas consideradas de alto impacto, são drasticamente menos citados do que os livros ou capítulos de livros (GINZBURG 2014). O alto ranqueamento de um periódico em sistemas de metrificação tem, portanto, pouco impacto para a contribuição efetiva de um artigo, tendo em vista que, mesmo sendo um parâmetro utilizado pelos autores na hora de submeter seus manuscritos para avaliação, ele não se coloca na hora da pesquisa e consulta (GINZBURG 2014). Além disso, deve-se também levar em consideração que a excessiva valoração da produção de artigos pode prejudicar a autonomia intelectual por meio de práticas que estimulam a quantidade em detrimento da qualidade e da inovação em detrimento da formação. Nesse movimento, outras importantes instâncias como a docência e a atuação pública do historiador possuem pouquíssima relevância dentro do sistema de pontuação da CAPES (ARAUJO 2016).

Ao logo deste artigo, fez-se um breve histórico da revista História da Historiografia, perscrutando a sua consolidação como periódico de referência na área de história da historiografia e teoria da história. Além disso, analisaram-se a formação e a composição do Conselho Executivo do periódico e do perfil dos artigos publicados, pincelando as novas mudanças que visam dar continuidade a esse recente e bem-sucedido projeto editorial brasileiro. Optou-se por analisar o perfil do Conselho Executivo, ao invés do Editorial, por acreditar que ele possui o 
papel propriamente efetivo de direção do periódico, delineando suas estratégias de inserção editorial. Observou-se que, no que tange à composição de seu Conselho Executivo, a maioria dos pesquisadores são homens (86\%); brancos (72\%); brasileiros ( $86 \%)$; lotados em instituições da região sudeste (75\%). O perfil principal dos autores de artigos é de homens $(68 \%)$; professores do ensino superior $(55 \%)$; adjuntos (41\%); vinculados a instituições brasileiras (70\%) situadas na região sudeste $(67 \%)$, que publicaram uma única vez no periódico (87\%). Os artigos são, em sua maioria, de autoria única $(92 \%)$; realizados sem financiamento $(67 \%)$; escritos em português ( $80 \%)$; pertencentes à história da historiografia e à teoria da história (67\%); voltados ao estudo de autores ou aspectos do Brasil (25\%); focados na idade contemporânea (77\%). A maioria dos autores estudados nos artigos publicados na História da Historiografia são do sexo masculino (95\%).

Após três anos de existência do periódico, seus editores viam o desenvolvimento da proposta inicial com entusiasmo, ao declarar que

a $H H$ é, hoje, um dos mais significativos loci editoriais da discussão teórico-historiográfica no cenário brasileiro, devendose destacar o potencial de internacionalização do periódico, visto que sua especialidade ultrapassa questões locais, regionais ou nacionais" (ASSIS; BENTIVOGLIO; GONTIJO 2011, p. 9).

Apesar do visível otimismo, a avaliação feita ainda em 2011 parece certeira. É inegável que a História da Historiografia vem cumprindo o seu papel de dar maior visibilidade à produção em história da historiografia e teoria da história e de se manter como centro de debate capaz de receber e concentrar os resultados dessas pesquisas. 


\section{REFERÊNCIAS BIBLIOGRÁFICAS}

ARAUJO, Valdei. Sobre o lugar da história da historiografia como disciplina autônoma. Locus: revista de história, v. 12, n. 1, p. 79-94, 2006.

História da historiografia como analítica da historicidade. História da historiografia, n. 12, p. 34$44,2013$.

- O regime de autonomia avaliativo no Sistema Nacional de Pós-Graduação e o futuro das relações entre historiografia, ensino e experiência da história. Anos 90, Porto Alegre, v. 23, n. 44, p. 85-110, 2016.

ASSIS, Arthur Alfaix; BENTIVOGLIO, Julio; GONTIJO, Rebeca. Editorial. História da historiografia, n. 7, 2011. . Editorial. História da historiografia, n. 8, 2012.

. Editorial. História da historiografia, n. 11, 2013.

BENTIVOGLIO, Julio. A Historische Zeitschrift e a historiografia alemã no século XIX. História da historiografia, n. 6, p. 81-101, 2011.

- Revistas de história: objeto privilegiado para se estudar a história da historiografia?. In: BENTIVOGLIO, Julio; ARRAIS, Cristiano Pereira Alencar. As revistas de história e as dinâmicas do campo historiográfico. Serra: Editora Milfontes, 2017, p. 7-30.

CALDAS, Pedro; MATA, Sérgio da; ARAUJO, Valdei. Editorial. História da historiografia, n. 6, 2011.

CEZAR, Temístocles. Editorial. História da historiografia, n. 15, 2014. 
FERREIRA, Ana Gabriela Clipes; CAREGNATO, Sônia Elisa. A editoração eletrônica de revistas científicas brasileiras: o uso de SEER/OJS. Transinformação, v. 20, n. 2 , p. 171-180, 2008 . Disponível em: http:// www.scielo.br/scielo.php?script=sci arttext\&pid $=$ S010337862008000200005\&lng=en\&nrm=iso. Acesso em 10 out. 2018. http://dx.doi.org/10.1590/S010337862008000200005 .

FICO, Carlos; WASSERMAN, Claudia; MAGALHÃES, Marcelo de Souza. Considerações sobre Qualis Periódicos - História. Ministério da Educação, Coordenação de Aperfeiçoamento de Pessoal de Nível Superior, Diretoria de Avaliação, 2016. Disponível em: http://capes.gov.br/images/ documentos/Qualis periodicos 2016/Consideracoes Qualis Periodicos Area $40 \quad 2016 \quad 08 \quad 08$ HIST\%C3\%93RIA.pdf. Acessado em: 21 nov. 2018.

GINZBURG, Jaime. Periódicos acadêmicos: antagonismo entre produção e leitura (notas sobre revistas da área de Letras publicadas em 2013). Expedições: Teoria da História e Historiografia, v. 5, n.1, 2014.

MELLO, Ricardo Marques de. Tendências historiográficas na Revista Brasileira de História, 1981-2000. 125 f. Tese (Doutorado em História)-Universidade de Brasília, Brasília, 2012a.

. O que é teoria da história? Três significados possíveis. História e Perspectivas, n. 46, p. 365-400, 2012b.

MIRANDA, Tiago C. P. dos Reis. Editorial. História da historiografia, n. 13, 2013.

MORENO, Ana Carolina. Negros representam apenas 16\% dos professores universitários. G1, Rio de Janeiro. 20 nov. 2018. Educação. Disponível em: https://g1.globo.com/ educacao/guia-de-carreiras/noticia/2018/11/20/negrosrepresentam-apenas-16-dos-professores-universitarios. ghtml. Acesso em 22 nov. 2018. 
NICODEMO, Thiago Lima; SANTOS, Pedro Afonso Cristovão dos; PEREIRA, Mateus Henrique de Faria. Uma introdução à história da historiografia brasileira (1870-1970). Rio de Janeiro: FGV, 2018.

. Brazilian historical writing in global perspective: on the emergence of the concept of "historiography". History and Theory, n. 53, p. 84-104, 2015. DOI: 10.1111/ hith.10780

OLIVEIRA, Maria da Glória de; GONTIJO, Rebeca. Sobre a história da historiografia brasileira: um breve panorama. R. IHGB, Rio de Janeiro, a. 177, n. 472: 13-38, 2016.

OS EDITORES. Editorial. História da historiografia, n. 3, 2010a.

n. 4, 2010b.

, n. 5, 2010c.

, n. 16, 2014.

, n. 26, 2018.

OSÉS, Mariana Ladeira. O trabalho que se faz: a atividade diretorial nos Annales d'Histoire Économique et Sociale (19291938). História da historiografia, n. 24, p. 60-76, 2017.

ROCHA, Sabrina Magalhães. Os periódicos e a crítica da história: a recepção de Lucien Febvre e Marc Bloch por seus contemporâneos (1911-1942). 2018. Tese (Doutorado em História). Instituto de Ciências Humanas e Sociais, Universidade Federal de Ouro Preto, Mariana, 2018.

SILVEIRA, Lúcia da; BENEDET, Lara; SANTILLÁN-ALDANA, Julio. Interpretando a internacionalização dos periódicos científicos brasileiros. Motrivivência, v. 30, n. 54, p. 90-110, 2018. Disponível em: https://periodicos.ufsc.br/index.php/motrivivencia/article/ view/2175-8042.2018v30n54p90. Acesso em: 07 set. 2018. doi: https://doi.org/10.5007/2175-8042.2018v30n54p90. 
TESNIÈRE, V.; BOUQUIN, C. Une morphologie de la circulation des savoirs la revue depuis 1800 . Revue de Synthèse, v. 135 , n. 2-3, p. 175-202, 2014. https://doi. org/10.1007/s11873-014-0251-1

TORRES, Luiz Henrique. O conceito de história e historiografia. BIBLOS, v. 8, p. 53-59, 2007. Disponível em: $\quad$ https://periodicos.furg.br/biblos/article/view/443. Acesso em: 24 set. 2018.

Sites

http://plsql1.cnpq.br/divulg/RESULTADO PQ 102003.prc comp cmt links?V COD DEMANDA $=200310 \& \mathrm{~V}$ TPO RESULT $=$ CURSO\&V COD AREA CONHEC $=70500002 \& \mathrm{~V}$ COD CMT ASSESSOR=HF Acesso em: 05 out. 2018.

http://www.ibict.br/pesquisa-desenvolvimentotecnologico-e-inovacao/sistema-eletronico-de-editoracaode-revistas-seer/historico Acesso em: 10 out. 2018.

https://pkp.sfu.ca/ojs/ojs-usage/ojs-map/. Acesso em: 10 out. 2018.

\section{AGRADECIMENTOS E INFORMAÇŌES}

\section{Flávia Florentino Varella}

flavia_varella@hotmail.com

Doutora em História (UFRGS)

Professora adjunta

Universidade Federal de Santa Catarina

Agradeço à Danielly Campos Dias pela coleta dos dados. 